\title{
Unshrouding: Evidence from Bank Overdrafts in Turkey
}

\section{SULE ALAN, MEHMET CEMALCILAR, DEAN KARLAN, and JONATHAN ZINMAN*}

\begin{abstract}
Lower prices produce higher demand... or do they? A bank's direct marketing to holders of "free" checking accounts shows that a large discount on $60 \%$ APR overdrafts reduces overdraft usage, especially when bundled with a discount on debit card or auto-debit transactions. In contrast, messages mentioning overdraft availability without mentioning price increase usage. Neither change persists long after the messages stop. These results do not square easily with classical models of consumer choice and firm competition. Instead they support behavioral models where consumers underestimate and are inattentive to overdraft costs, and firms respond by shrouding overdraft prices in equilibrium.
\end{abstract}

Many business models in financial services and other industries rely on expensive add-ons that are tied to base goods. Examples include expensive overdraft credit (add-on) tied to a "free" checking account (base good), back-end management fees tied to "free" investment advice, printer cartridges and printers, luggage fees and airline tickets, and dealer-supplied maintenance and automobiles. A closely related practice is overage/penalty pricing.

\footnotetext{
* Contact information: Sule Alan: salan@essex.ac.uk, University of Essex and Koc University; Mehmet Cemalcılar: mcemalcilar@ku.edu.tr, Koc University; Corresponding author - Dean Karlan: dean.karlan@yale.edu, Yale University, IPA, J-PAL, and NBER; Jonathan Zinman: jzinman@dartmouth.edu, Dartmouth College, IPA, J-PAL, and NBER. We thank Yapi Kredi staff for their cooperation; Michael Grubb, Ben Keys, David Laibson, Eva Nagypal, Josh Schwartzstein, Andrei Shleifer, and audiences at Boston College, Harvard/MIT, Kellogg (Finance), LSE, UCL, University of Maryland, University of Virginia, the Federal Reserve Bank of Philadelphia, the CFPB Research Conference, and the NBER Law \& Economics group for comments; and Benni Savonitto, Glynis Startz, and Zachary Groff for research management and analysis support. Authors did not have direct conflicts of interest but are associated with other entities concerned with overdraft fees. Disclosure information is available online.
}

This article has been accepted for publication and undergone full peer review but has not been through the copyediting, typesetting, pagination and proofreading process, which may lead to differences between this version and the Version of Record. Please cite this article as doi: 10.1111/jofi.12593.

This article is protected by copyright. All rights reserved. 
Businesses with such revenue models typically focus their marketing and competitive strategy on the base good, even though add-ons/overages can be critical revenue sources.

Retail banking provides a striking example: banks often market checking accounts as free, even though many consumers end up paying high fees for overdraft credit. ${ }^{1}$ Government audits find that banks rarely market overdraft services at the customer acquisition stage and even actively discourage employees from providing information on overdraft terms (General Accounting Office (2008), Competition and Markets Authority (2014), Consumer Financial Protection Bureau v. TCF National Bank (2017)). After acquiring customers, banks in some markets including Turkey, the site of our experiment, blur the line between positive and negative balances by highlighting for customers an available-to-withdraw figure that adds the available overdraft credit line amount to the checking account balance, while making information on disaggregated balances and finance charges more difficult to find. Turkish banks during our study period basically drew attention to overdrafts only when promoting the feature to existing customers. Yet even those promotions did not explicitly mention the price of overdraft credit.

Why would a bank hide information on overdraft costs? After all, a classically rational consumer would simply infer that shrouded prices are high prices. But recent behavioral theories show that shrouded and high prices can persist if consumers tend to underestimate their add-on costs and firms cannot profit from de-biasing consumers with more transparent

\footnotetext{
${ }^{1}$ An overdraft occurs if the checking account holder initiates a transaction that makes her balance negative or more negative.
}

This article is protected by copyright. All rights reserved. 
pricing or information about competitors' high add-on prices (Gabaix and Laibson (2006), Grubb (2015), Heidhues, Köszegi, and Murooka (2017)). ${ }^{2}$

Bank regulators respond to such practices in various ways. For example in the U.S. regulators require upfront consumer opt-in for debit card and ATM overdrafts, in both the U.S. and U.K. regulators caution banks against relying too heavily on overdraft, and in Turkey regulators cap overdraft prices.

Empirical evidence, however, is lacking on key questions raised by theory and policy. Do consumers actually underestimate costs of add-ons such as overdrafts? Do firms actually have incentives to shroud add-on prices instead of competing to de-bias consumers? How do consumers allocate attention to add-ons? and how quickly does consumer learning about addons break a shrouded equilibrium? In short, empirical evidence on what drives overdraft pricing, advertising, and usage is limited and largely descriptive.

These questions are central to overdraft markets. Beginning in the 1990s, overdraft revenue replaced monthly subscription fees as banks' major source of explicit income from checking accounts, shifting the pricing equilibrium for retail banking in much of the world to "free if nonnegative balance, very expensive if in overdraft." In the U.S., banks collect more than $\$ 10$ billion in overdraft revenue annually. In the UK, banks derive almost as much income from overdrafts as from re-investing checking account deposits (Competition and Markets Authority 2014). In Turkey, the site of our experiment, the announcement of a price

\footnotetext{
${ }^{2}$ For related evidence on consumer perceptions of overdraft costs, see Armstrong and Vickers (2012) and Stango and Zinman (2014). For related models of limited and reactive consumer attention, see, for example, Gabaix (2014) and Bordalo, Gennaioli, and Shleifer (2015).
} 
ceiling on overdrafts was immediately followed by a $1.4 \%$ reduction in bank share prices, with a $2.1 \%$ drop for the most overdraft-reliant bank (Toksabay (2013)).

We worked with Yapi Kredi (YK), one of the largest banks in Turkey, to design a randomized direct marketing experiment that distinguishes between classical and behavioral models of add-on pricing and advertising. YK sought to learn more about its optimal strategy for pricing and advertising its overdraft product. The last was particularly interested in understanding whether its past promotional pricing and advertising content tactics were effective in increasing demand, and if not why not. YK's interest rate $(60 \%$ APR) and product design was in line with standard practices and regulations. As is common in overdraft markets, the product was priced expensively relative to seemingly close substitutes (like credit cards), and disproportionally to credit risk (as recently found by Turkish authorities).

YK sought to target marginal overdrafters among its existing client base, and hence the experiment varied the promotions that YK sent via SMS from September to December 2012 to 108,000 existing checking account clients who had not overdrafted during the previous few months. These clients are likely representative of a substantial population of marginal overdrafters in Turkey, and they share key characteristics with "banked" populations in both more- and less-developed countries.

The experimental design produces random variation, both across clients and over time, in overdraft prices and in messaging content, frequency, and duration (see Figure 1). Our tests rely on overdraft-usage comparisons across groups receiving different promotions, since Turkish banks frequently use SMS-based promotions (a pure control group would be offequilibrium). The key comparison is between overdraft-promoting messages that mention price and those that do not. 
[FIGURE 1. Experimental design]
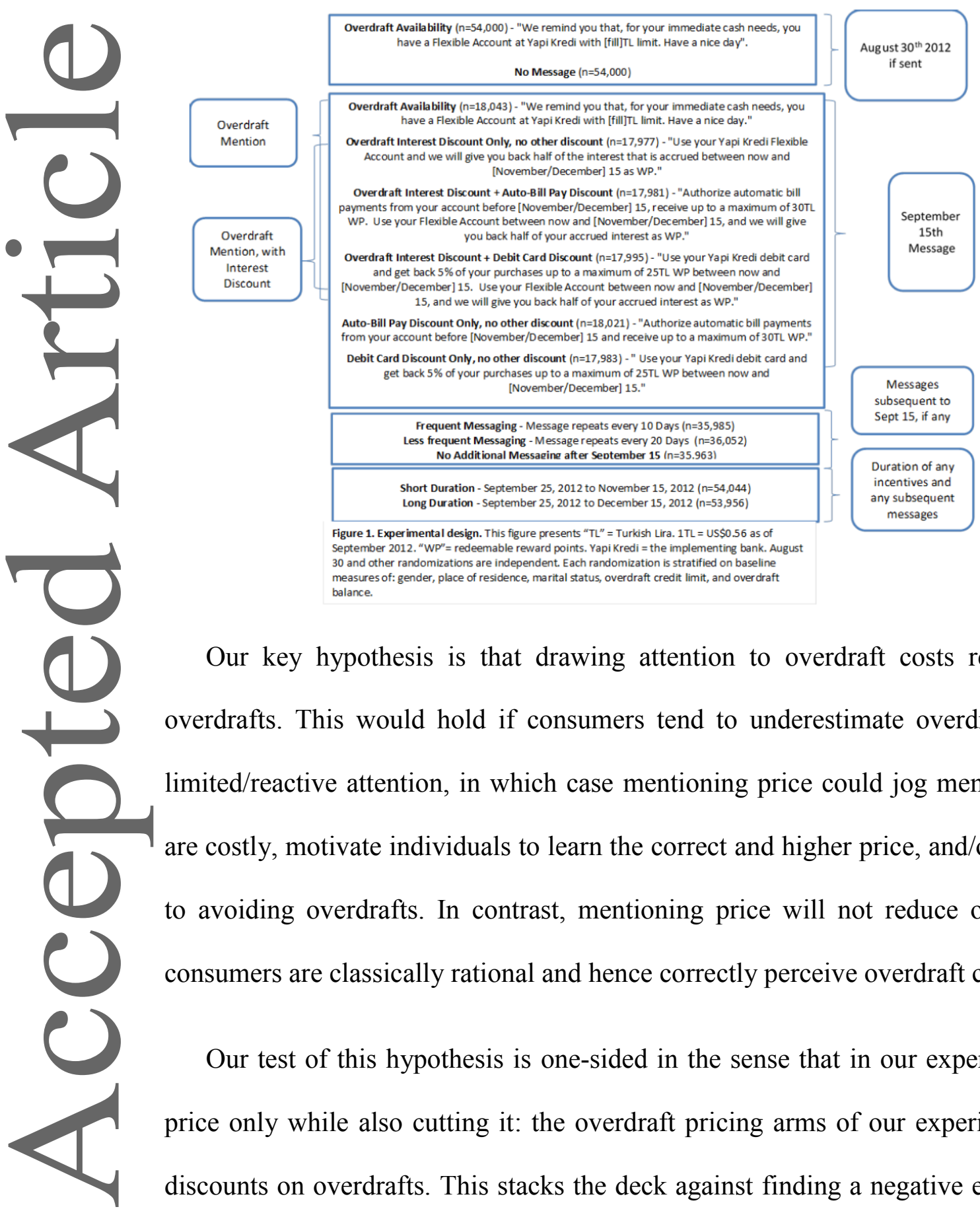

Our key hypothesis is that drawing attention to overdraft costs reduces demand for overdrafts. This would hold if consumers tend to underestimate overdraft costs and have limited/reactive attention, in which case mentioning price could jog memory that overdrafts are costly, motivate individuals to learn the correct and higher price, and/or increase attention to avoiding overdrafts. In contrast, mentioning price will not reduce overdraft demand if consumers are classically rational and hence correctly perceive overdraft costs on average.

Our test of this hypothesis is one-sided in the sense that in our experiment YKmentions price only while also cutting it: the overdraft pricing arms of our experiment all offer $50 \%$ discounts on overdrafts. This stacks the deck against finding a negative effect of mentioning overdraft price, since even a behavioral consumer who is susceptible to shrouding presumably prefers lower prices. Yet we still find that mentioning overdraft price lowers overdraft demand. For example, the likelihood of overdrafting during the experiment is 1.2 percentage points lower ( $\mathrm{se}=0.4$ percentage points) for those receiving the discount offer 
relative to those receiving a message that mentions overdraft without also mentioning its price, on a baseline likelihood of $31 \%$.

Another behavioral hypothesis is that bundling the overdraft discount with a discount on debit card or automated bill-payment usage further depresses demand. The idea is that mentioning overdrafts together with transactions that could trigger overdrafts could be a particularly powerful reminder to avoid such transactions, akin to the attention-by-association findings in Stango and Zinman (2014). ${ }^{3}$ Again, both classical and mechanical forces work against finding support for this hypothesis; in the absence of behavioral factors, the bundled discounts should generate weakly more outflows from the checking account, producing weakly more variance in the checking account balance and hence weakly more overdrafts. Nevertheless, we continue to find support for the behavioral hypothesis. Offering the overdraft discount alone reduces overdraft likelihood by only 0.7 percentage points $(\mathrm{se}=0.5)$ relative to messages that mention overdraft without also mentioning price, while the bundled reductions are 1.4 percentage points for automated bill payment $(\mathrm{se}=0.5)$ and 1.7 percentage points for debit card ( $\mathrm{se}=0.5)$.

Importantly, discounts on the bundled products themselves do not backfire in the same way that overdraft discounts do: offering a discount for debit card usage or automated billpayment authorization weakly increases demand for those services. These results further highlight the distinction between advertising shrouded attributes (overdraft) versus unshrouded attributes (debit or autopay).

\footnotetext{
${ }^{3}$ Stango and Zinman (2014) find that drawing consumer attention to spending control, monitoring account balances, or other bank fees leads to overdraft reductions.
}

This article is protected by copyright. All rights reserved. 
As noted above, our experimental design also includes an overdraft availability promotion that does not mention price. We can identify its effects on demand by comparing it to messages that do not mention overdraft at all (they promote debit or automated bill-payment transactions alone). We find that the overdraft availability message increases overdraft likelihood, by about 0.9 percentage points $(\mathrm{se}=0.4)$. We do not find heterogeneous effects based on prior overdraft experience (although the confidence intervals do not rule out meaningful differences), suggesting that overdraft availability is not salient/top-of-mind even if the consumer is already informed about availability in some classical sense. This finding suggests that, after acquiring a customer, firms can promote non price aspects of add-ons without drawing attention to costs.

Together, our results are consistent with models of shrouded equilibrium and limited/reactive consumer attention. In particular, they support (1) the key modeling assumption that consumers tend to underestimate add-on costs (if consumers' estimates were unbiased then offering a discount would weakly increase demand), (2) the key assumption that firms lack incentives to unshroud prices, (3) a key prediction of reactive attention models that consumers respond differently when advertising highlights different add-on attributes (price or availability). Shifts from shrouded to unshrouded equilibria may therefore be costly to generate and sustain. In section $\mathrm{V}$ we discusses alternative, more classical interpretations, and why they do not provide as complete an explanation of our setting and results.

Our paper informs several other literatures on limited attention, salience, and advertising. First, our results provide insights into what comes to mind and what does not (Bordalo, Gennaioli, and Shleifer (2013), Eliaz and Spiegler (2011), Gabaix (2014), Hanna, Mullainathan, and Schwartzstein (2014), Karlan et al. (2016)). Second, our resultsshow that price promotions have attention effects that can backfire from the promoter's perspective, 
thereby adding evidence to literatures on the psychology of incentives (Gneezy and Rustichini (2000), Kamenica (2012)) and price changes (Hastings and Shapiro (2013)) that have not yet focused much on shrouded prices. Our results are consistent with findings from other domains suggesting that consumers respond differently to base prices and add-on prices (Anagol and Kim (2012), Brown, Hossain, and Morgan (2010), Chetty, Looney, and Kroft $(2009))^{4}$

Relatedly, our findings contrast with those in Ferman (2016) and Elizondo and Seira (2017), who find little impact of messaging in Brasil and Mexico, respectively that makes the base price of high-interest credit cards more prominent. Our results are broadly consistent with prior workthat shows advertising content can have important and surprising effects on decisions about expensive debt (Bertrand et al. (2010)), and that messaging from banks can change the behavior of existing customers (Cadena and Schoar (2011), Karlan, Morten, and Zinman (2015), Kast, Meier, and Pomeranz (2016)). Our results on the long-run effects of short-run messaging complement the literature on the dynamics of learning and/or attention regarding add-on charges (Agarwal et al. (2013), Ater and Landsman (2013), Haselhuhn et al. (2012), Stango and Zinman (2014)), may help explain why advertising is so prevalent (treatment effects dissipate quickly and hence repeated exposure matters), and suggest that

\footnotetext{
${ }^{4}$ We do not actually observe price sensitivity to the base price in our setting. But given our result that cutting overdraft prices depresses overdraft demand, we can infer differential sensitivity to base and add-on prices simply by assuming that cutting the base price would not decrease demand for checking accounts.
}

This article is protected by copyright. All rights reserved. 
short-run behavior changes do not necessarily induce learning or greater sophistication about attention (Schwartzstein (2014), Manoli and Turner (2015)). ${ }^{5}$

The rest of the paper is arranged as follows. Section I describes the overdraft market in our study site, Section II explains our experimental design and describes our sample. We present our empirical results in Section III, and provide a detailed discussion in Section IV. Finally, Section V concludes. The appendix provides figures and tables with additional results.

\section{Setting: The Overdraft Market in Turkey}

We discuss the economic importance of overdrafts in the introduction. Here we describe our partner bank, YK, and the Turkish overdraft market. Our setting has many similarities to overdraft markets in other countries like the U.S. and UK, with a key

\footnotetext{
${ }^{5}$ Stango and Zinman, (SZ, 2014) is probably the most closely related empirical paper to ours. SZ use quasi-experimental variation in survey content in a market research panel in the U.S. to identify effects and dynamics of attention to overdraft fees. Similar to here, SZ find that an attention shock mentioning overdraft costs reduces overdraft usage, and that repeated attention shocks cumulate to some extent, although they depreciate more quickly in our setting. Aside from the obvious differences between the two study designs - market research surveys versus bank advertising as attention shocks, quasi-random versus random variation, U.S. versus Turkey-there are at least two other key differences. First, we have randomly assigned price variation. Second, our treatments include some messages that mention the overdraft service but not its cost. These differences lead to the surprising new inferences that bringing overdrafts to mind increases demand, but bringing the price of overdrafts to mind, even if accompanied by a discount, lowers demand. See also Liu, Montgomery, Srinivasan (2014) and Hunt, Kelly, Garavito (2015).
} 
difference being substantially lower prices in Turkey $(60 \%$ APR versus $\$ 25$ to $\$ 40$ pertransaction fees for very small and short-term loans). ${ }^{6}$

\section{A. Retail and Mobile Banking in Turkey}

Turkey's retail/consumer banking industry is concentrated. Only about 30 banks are licensed to take deposits, and the five largest banks have greater than 50\% market share. YK is in the top five based on both total assets and number of branches, and is publicly traded. In recent years the Turkish market has become known for innovation in retail banking, with one bank rolling out the largest biometric ATM network in the region, and another bank becoming the first in the world to make money transfers possible on Facebook. Turkey has the highest rate of mobile banking in Europe among internet users, at around 50\%, according to a 2013 ING survey, and $91 \%$ of Turkish adults have a cell phone, for one of the highest penetration rates in the world.

\section{B. Overdraft Practices}

The focus of our experiment is a checking account overdraft product, which YK brands the "Flexible Account," with features that were standard in Turkey (and throughout the world) during our study period. The product is an unsecured line of credit that allows

\footnotetext{
${ }^{6}$ For details on overdraft markets in the U.S. and Europe, see, for example, Stango and Zinman (2014) and various government reports (Bakker et al. (2014), Competition and Markets Authority (2014), Financial Conduct Authority (2014), General Accounting Office (2008)). For policy developments in the U.S. and EU, see, for example, FDIC Supervisory Guidance warning banks about the risks of "excessive use" of overdrafts by customers and "maximizing fees" by banks, Dougherty (2014), and the European Parliament's Directive on Payment Accounts (issued April 2014).
}

This article is protected by copyright. All rights reserved. 
qualifying customers to overdraw their account (i.e., to hold a negative balance) at a cost of $60 \%$ APR on outstanding credit (about $50 \%$ after adjusting for inflation). Credit card APRs tend to be substantially lower. The bank approves about 55\% of checking account customers for the overdraft feature, with credit limits that vary based on underwriting but that are typically lower than other unsecured credit products. Although individuals can apply for the overdraft feature, which typically (and in our study) the bank automatically chooses individuals to be given the feature, which thus requires individuals opt-out if they do not want it rather than opt-in if they do. Customers then use the line, automatically, any time their checking account falls (further) below zero. Negative balances begin accruing interest immediately. By law, any inflow to the checking account is automatically allocated first toward paying off overdraft credit. If inflows are not sufficient to clear the balance by the end of the statement date (four weeks), the bank sends the customer a notice and gives them about two weeks to pay at least the accrued interest. If the customer fails to make the required payment after 60 days, the bank freezes the overdraft line.

Overdrafts have attracted regulatory scrutiny because they-and their prices-are rarely featured at the customer acquisition stage, and often are not fully disclosed even postacquisition. Pre-acquisition, we are not aware of any mass marketing campaigns promoting overdraft usage during our sample period in Turkey. Regulators have found that when banks did communicate with (prospective) consumers, they often failed to provide mandated disclosures or did so only perfunctorily.

Communications with existing customers also indicate a (partially) shrouded equilibrium during our sample period. Customers lacked easy access to information on their own overdraft usage and charges. Banks did not routinely issue monthly statements, due to the unreliable postal system, and electronic notifications of overdraft usage did not mention 
the interest rate. Electronic banking was and is the dominant channel for customers getting information on their accounts, and online information on overdraft usage was folded into the customer's main transaction record rather than disaggregated. The transaction record would specify the amount charged in overdraft interest, but not the interest rate. Landing pages - the first screen the customer sees after logging in online or at an ATM- would obscure whether overdraft was being used by highlighting the customer's balance based on 'available-towithdraw" (including credit line) instead of just the checking account balance. A customer seeking interest rate information would need to either navigate through several different screens or contact a customer service representative. Banks promoted overdraft usage to existing customers in direct messaging campaigns, but those campaigns did not mention the level of the interest rate even when offering discounts on that rate; for example, an ad would say "half off your interest charges" instead of "half off your $60 \%$ interest rate."

\section{Overdraft Users and Usage in Turkey}

Who overdrafts? In Turkey there are not much data on the characteristics of overdrafters (e.g., our data lack information on education or income), but there are some clues. Over half of Turkey's population is unbanked, according to a 2012 World Bank report. Moreover, many checking account holders are not approved for overdraft lines of credit due to credit risk that banks cannot price. These facts together suggest that overdrafters come from the upper half of the income distribution in Turkey, although not from the uppermost percentiles, who presumably have wealth and access to cheaper credit that would tend to render overdrafting unlikely and/or relatively unattractive.

Our customer sample overdrafts frequently in the ten months after our experiment started, despite having been selected for the experiment based on infrequent overdraft activity prior to the experiment (Section III. B; Table I). In any given month $15 \%$ to $24 \%$ of our 
sample overdrafts and $45.8 \%$ of our sample overdrafts at least once between September 1 , 2012 to June 30, 2013, paying a mean finance charge of $30.82 \mathrm{TL}(1 \mathrm{TL}=\$ 0.56$ USD during our sample period) over the ten months, (the $95^{\text {th }}$ percentile is $228.08 \mathrm{TL}$ ).

The sharp increase in overdrafting from baseline to (post-) experiment is probably not due to mean reversion, as overdrafting tends to be strongly serially correlated month-tomonth. Rather, discussions with YK and its regulators point to a market-wide increase that flowed from easy monetary policy to widespread promotions by consumer lenders around the end of Ramadan to overdrafts spurred by subsequent difficulties marginal borrowers had in managing their increased debt service. In any case, the sharp increase in overdrafting is evident in both aggregate data and YK's customer base. YK held back a no-message group of 39,000 customers from our experiment, and Figures 2 panels A and B, show similar trends in overdraft usage for this group compared to our experimental group of 108,000 customers. ${ }^{7}$

[FIGURE 2: Overdraft Usage over time (panel A and panel B)]

\footnotetext{
${ }^{7} \mathrm{YK}$ applied somewhat different and not entirely reproducible filters in selecting the no-message comparison group, so we do not use this group as a pure control group for analysis purposes. Creating a pure, randomized control group was not a point of emphasis at the design and implementation stages of the experiment, since the equilibrium was one of extensive direct messaging and hence the mapping of message versus no-message comparisons to theory is less clear than comparisons across different promotions.
}

This article is protected by copyright. All rights reserved. 
As noted above, overdraft practices have been attracting legal scrutiny around the globe. In July 2013, seven months after our experiment ended, the Turkish Competition Authority found that banks were benefiting from substantial markups over risk-based prices and fined 12 banks for price-fixing on loans, including overdrafts. On May 27, 2013, the Turkish Central Bank imposed a binding price ceiling on overdraft APR. Turkish regulators have also focused on marketing and communications since our experiment ended, pressuring and working with banks to make overdraft usage, pricing, and costs more transparent.

\section{E. Ethics of Experimenting with High-Cost Credit}

In seminars we are frequently asked whether researchers should partner with a lender that is seeking to sell more high-interest rate loans. We think yes, in this circumstance as in many related experiments on microcredit where take-up is an outcome of interest, for four main reasons. First, an ethical concern here presumes that high-cost consumer credit harms consumers. But extensive research on this question suggests that a different assumption is warranted- (weakly) beneficial impacts for consumers (Karlan and Zinman (2010), Zinman (2014), Banerjee, Karlan, and Zinman (2015)). Second, YK's advertising was truthful and its terms were competitive. Thus, combining the first and second points, the experiment was not trying to convince consumers to accept a bad deal either in absolute terms or compared to market alternatives. Third, YK was going to promote overdraft usage among its existing customers with or without the participation of the research team and we helped convince bank management to feature prices despite its skepticism about the effectiveness of past overdraft price promotions. Fourth, YK and the research team contracted ex-ante that the academic co-authors would have unrestricted intellectual freedom to report the results and disseminate them publicly to benefit regulators and further scientific knowledge.

\section{Experimental Design, Sample, and Data}

This article is protected by copyright. All rights reserved. 


\section{A. Experimental Design and Implementation}

Figure 1 summarizes the experimental design and details the script of each message variant. The field experiment randomly assigns message content, frequency, and duration, as well as promotional offers on overdraft, debit card, and automated bill payment, to a sample of 108,000 checking account holders. YK did not send this sample any other promotional communications during this campaign. The only other communications YK sent to this sample were monthly account statements. YK sent the messages by SMS, which is the most common way banks communicate with their clients in Turkey.

YK began the experiment by sending half of the sample an "Overdraft Availability" message on August 30, 2012 that mentions the overdraft service and credit line but nothing about its cost. $^{8}$ This first randomization is not crucial for testing our main hypotheses; it served primarily as a pilot for the subsequent randomizations and a test for a heterogeneous treatment effect suggested by some of the motivating theoretical models (Section IV).

YK continued the experiment on September 15, 2012 with a second, independent randomization, sending each person in the sample one of six randomly assigned promotions. Half of the sample received one of the three "Overdraft Interest Discount" messages detailed in Figure 1, with one-third of this group (or of this half) getting only an overdraft discount, one-third getting an overdraft discount plus an automated bill payment discount, and one-

8 "We remind you that, for your immediate cash needs, you have a Flexible Account at Yapi Kredi with [custom fill]TL limit. Have a nice day." One might think of this message as a "reminder" because the bank's policy and Turkish law require upfront disclosure of the overdraft features and pricing. However, given that the service is offered on an opt-out basis, and that our motivating questions concern shrouding prices, we allow for the possibility that this message provides new information rather than being a simple reminder. We explore this possibility in Section IV. 
third getting an overdraft discount plus a debit card discount. The other half of the sample did not get an overdraft interest discount, with one-third of this half getting the automated bill payment discount only, one-third getting the debit card discount only, and one-third getting only the overdraft availability reminder message described above.

An independent frequency randomization determined whether YK re-sent the September 15 message frequently (every 10 days), less frequently (every 20 days), or not again during the campaign period. A campaign duration randomization then determined whether the price promotion(s) or overdraft availability reminder, and any repeated messaging subsequent to September 15, lasted until November 15 or December 15.

Note that YK sent at least one message to everyone in our sample during the experiment. YK preferred this design feature because, like other banks, it often sends promotional and reminder messages to its customers and thought it would be counterproductive to scale back directed advertising to zero. The research team also preferred this design — placebo communications with respect to overdraft, rather than pure controlbecause any contact from YK could trigger the customer's attention and affect her usage of YK products. $^{9}$

\section{B. Baseline Data on Sample Characteristics, and Balance Checks}

YK sought to promote overdraft usage among existing clients who it deemed most likely to be close to the margin of overdrafting. To this end it selected customers for the experiment based on the following criteria: owned a YK checking account for at least a year,

\footnotetext{
${ }^{9}$ A closely related way of framing our interest in placebo communications is that frequent directmessaging is the equilibrium, but we thought that the experiment would link more tightly to theory if the only deviations from equilibrium were around (partial) unshrouding.
}

This article is protected by copyright. All rights reserved. 
were in good standing in the account, and had a debit card linked to it; had an active cell phone; maintained an average total deposit account balance $<5,000 \mathrm{TL}$ over the three months prior to the start of the experiment (May toJuly 2012); did not have more than three automated bill payments set up; and already had the overdraft service in place but had not used it during the prior three months. Many of these customers did have some experience with the product before the three-month period prior to the experiment. Our pre-treatment data go back as far as September 2011, and from September 2011 to April 2012 18.4\% of our sample overdrafted at least once, with an average daily overdraft balance of 4.42TL (SD 23, Max 940) among these accountholders.

Table I summarizes the baseline data available to us (Column (1)) and checks balance across treatment assignments (Columns (2) to (10)). In terms of demographics, we have information only on gender ( $29 \%$ female), city of residence (28\% Istanbul, $23 \%$ outside the four largest cities), and marital status (57\% married). This information is collected by the bank at the account-opening stage and can be updated later by the client. Besides pretreatment data on overdraft usage (described above and in Table I), we also have data on the other behaviors targeted by the experiment: debit card usage and automatic debits for bill payments. We stratified on each of these baseline variables. The last column confirms that none of them is correlated with treatment assignment by regressing each row variable on the treatment assignments indicated Columns (2) to (10).

\section{Follow-Up Data}

YK provided us with data on overdraft usage, debit card usage, automated bill payment authorizations, and deposit account balances, at the account-month level, from September 1, 2012 through the end of June 2013 (although we do not use the June 2013 data due to the binding price cap imposed at the end of May 2013). In addition to the monthly 
data, YK provided us with daily data on overdraft usage for the experimental period, September 15 toDecember 15,2012 . We use these data to construct outcome variables for estimating the short-run and longer-run treatment effects detailed below.

\section{Hypotheses and Tests}

Our main hypothesis is that drawing attention to the cost of overdrafting will depress demand for it. The motivation for this hypothesis comes from two key features of behavioral models of costly add-ons like overdrafts. First, consumers tend to underestimate, and have limited/reactive attention to, add-on costs. ${ }^{10}$ Mentioning price could thus jog memory that overdrafts are costly, motivate individuals to learn the correct and higher price, and/or increase attention to avoiding overdrafts. Any of these channels could lead the consumer to revise her cost estimate upward and reduce her overdraft usage. In contrast, drawing attention to overdraft cost will not reduce demand if consumers are classically rational and hence correctly perceive overdraft costs on average. Second, and closely related to the demand

${ }^{10}$ Consumers can underestimate the price conditional on overdrafting (perhaps because they anchor on substantially lower prices for other bank services or sources of short-term credit), and/or underestimate the likelihood of overdrafting (perhaps they perceive it to be zero because they assume the bank will not let them overdraft, or perhaps they are overconfident about avoiding overdrafts). Grubb (2015) assumes that consumers perceive the price accurately but underestimate the likelihood of overdrafting, because they underestimate their cost of attention to balances. See also Grubb (2009). In terms of the other models most closely related to our setup, Gabaix and Laibson (2006), Heidhues, Köszegi, and Murooka (2017), and Bordalo, Gennaioli, and Shleifer (2015) assume that some consumers underestimate a reduced-form add-on cost that, in our setting, is the product of the price of overdrafting and the expected number of overdrafts (or, on the extensive margin, the product of the price of overdrafting and the likelihood of overdrafting).

This article is protected by copyright. All rights reserved. 
response in the first feature, unshrouding costs (e.g., by drawing consumer attention to them) may be unprofitable for the add-on supplier.

We test this hypothesis by comparing overdraft usage during the experimental period between customers sent an Overdraft Interest Discount message and customers sent an Overdraft Availability message. Both types of message promote overdraft usage, but only the Discount message says anything about the price. As noted in the introduction, this test actually stacks the deck toward rejecting our main hypothesis because the Discount message does not simply draw attention to overdraft costs, but also cuts the price in half. ${ }^{11}$ As such, accepting the hypothesis that the Overdraft Interest Discount message reduces demanddespite offering a much lower price- would be an especially strong indication that add-on price advertising unshrouds add-on costs for consumers, leading consumers to sharply revise their cost perceptions upward depressing demand for the add-on, and proving unprofitable for the supplier.

A second behavioral hypothesis is that bundling the overdraft discount with a discount on debit card or automated bill-payment usage will depress demand further. The idea is that mentioning overdrafts together with transactions that can trigger overdrafts could be a particularly powerful reminder to avoid overdrafts, akin to the findings in Stango and Zinman (2014) that drawing consumer attention to spending control mechanisms to monitor account balances, or other bank fees leads to overdraft reductions. Again, both classical and mechanical forces work against finding support for the behavioral hypothesis: in the absence of inattention the bundled discounts should generate weakly more outflows from the checking

\footnotetext{
${ }^{11}$ It would have been theoretically and statistically desirable to have experimental arms that simply mentioned the price of overdrafting without cutting it, and/or that mentioned the regular price $(60 \%$ APR) while cutting it, but YK deemed such messaging too far off-equilibrium to be viable.
} 
account, producing weakly more variance in the checking account balance and hence weakly more overdrafts.

We test this bundling hypothesis by comparing overdraft usage, during the experimental period between customers sent an Overdraft Interest Discount only message and customers sent an Overdraft Interest Discount message that also includes a discount for automated bill payment or debit card use. ${ }^{12}$

Third, we hypothesize that promoting overdraft availability, without mentioning price, will change demand. Classically rational consumers will have accurate perceptions of overdraft availability, at least on average, and should not respond. In contrast, behavioral mechanisms could generate either a negative response if advertising availability brings overdraft costs to mind, or a positive response. A positive response could arise if the overdraft service generally, and not just its cost, is not at top of mind for consumers. If consumers have reactive attention, then drawing attention to a positive feature of the service - its availability when one is short on cash — can increase demand for it. Another potential mechanism is that the message operates on consumers who thought that overdrafting was impossible and thus perceive zero likelihood and an infinite price of overdrafting. In this case the availability message could increase demand if it reduces the perceived price by more than it increases the perceived likelihood. We note that this mechanism would still be consistent with consumers underestimating overdraft costs at baseline, since impossibility implies zero expected cost.

\footnotetext{
${ }^{12}$ This is a conservative test of the hypothesized behavioral mechanism: the bundled messages are longer, and if longer messages tax limited attention, we would expect them to push treatment effects on overdrafting toward zero instead of further depressing demand. Ignoring a message makes it akin to getting no message at all.
} 
We test whether and how promoting overdraft availability affects demand by comparing overdraft usage among customers sent the Overdraft Availability message to customers sent messages that promote only debit card or automated bill-payment usage and do not mention overdraft at all.

Our final hypothesis focuses on understanding the dynamics of attention and overdraft behavior. The dynamics shed light on whether consumer learning and/or persistent attention to add-on costs break a shrouded equilibrium. For example, in Heidhues, Köszegi, and Murooka (2017) the profitability of high add-on prices is "limited by consumers' ex-post demand response to add-on prices" (p. 341), raising the possibility that, at the customer level, the firm wants to shroud at the customer acquisition stage but then unshroud while cutting the price of the add-on. In contrast, consumer forgetting and/or reactive attention to add-on costs increases the cost of de-biasing consumers, flattens or even reverses standard demand responses, and can make a shrouded equilibrium more durable.

To test the dynamics, we examine data from the post-campaign period (January to May 2013). Treatment effects will persist if consumer learning or attention with respect to add-ons is durable. Treatment effects will not persist if consumers quickly forget about addons or only attend to them when induced to do so by external stimuli like advertising.

\section{III.Specifications and Results}

We estimate OLS regressions at the level of YK's randomizations - the checking account, indexed by $i$ - and a timeframe that corresponds to either during- or post-experimental advertising (indexed by $t$ ):

$$
Y_{\mathrm{it}}=T_{\mathrm{i}} \beta+X_{\mathrm{i}} \alpha+e_{\mathrm{it}}
$$


where $Y$ is some measure of a behavior targeted by the marketing campaign (overdraft usage, debit card usage, or an automatic debit for bill payment) In Tables II and III we measure outcomes over a time period designed to capture immediate/short-run treatment effects: $t$ covers September 15 to December 31, since the bank sent everyone at least one promotional message starting September 15 and sent the last promotional messages on December 15 . Table IV measures outcomes over the post-experiment period, January 2013 to May 2013.

$T$ is a vector of treatment assignments (see Figure 1), with $\beta$ the vector of estimated coefficients on those treatment variables and $X$ is a vector of the stratification variables used to block the randomization (see Table I).

Our main tables define the treatment vector to test our main hypothesis with the simplest possible presentation. In particular, we make use of additive specifications that enable us to keep the omitted treatment category consistent across columns within each table, and to facilitate inference about comparisons of theoretical interest: overdraft promotions that mention price versus those that do not (rows (4) to (7) in Tables II and IV), and price promotions on other banking services that are bundled with overdraft discounts versus those that are not (rows (2) and (4) in Table III). The Appendix presents a more comprehensive set of results.

\section{A. Main Effects of Overdraft Promotions on Overdrafting, During Experiment}

Table II presents the estimated effects of the different overdraft promotions on three measures of overdraft usage during the experimental period (September 15 to December 31, 2012).

Rows (1) and (3) estimate effects of the Overdraft Availability message, which does not mention costs or offer a discount. This message increases demand for overdraft relative 
to not getting a message on August $30^{\text {th }}$ (rows (1) and (2)), and relative to messages that do not mention overdraft (row (3)). ${ }^{13}$ The magnitudes are on the order of 1 percentage point in 1/0 usage, 0.1 days with an overdraft balance, and 1TL in average overdraft balance. These results support the hypothesis that promoting overdrafts without reference to cost increases demand, the most straightforward interpretation of which is that consumers have limited and reactive attention to all aspects of the overdraft service, not just to its cost.

Row (4) presents estimates of the effect of getting an overdraft interest promotion relative to getting the Overdraft Availability message, which does not mention price. Reading across columns one can see that this effect is negative — offering a lower price leads to lower demand - with estimates for two of the three demand measures having $p$-value $<0.01$. The extensive margin decreases by 1.2 percentage points $(\mathrm{se}=0.4)$, and days with a balance falls by $0.16(\mathrm{se}=0.05)$, for declines of $4 \%$ and $6 \%$ relative to the sample means. These results support the hypothesis that drawing attention to overdraft costs reduced demand (even while offering a $50 \%$ discount!), with the key implications being that consumers tend to underestimate overdraft costs and banks lack incentives to unshroud or compete on overdraft prices because doing so backfires. ${ }^{14}$

\footnotetext{
${ }^{13}$ One might wonder whether the "Have a nice day" portion of the availability message might be driving the effects rather than a reminder about availability per se, but if this were the case one might expect to see customers responding to the bank's friendliness by using other banking services more. We do not find any such evidence (see appendix Table A II, row (3)).

${ }^{14}$ In Appendix Table AI we confirm that lower demand likely maps into lower profitability for the bank, as we do not find any evidence that account balances increase to offset lost overdraft revenue with increased implicit interest. Stango and Zinman (2014) also infer that consumers do not engineer overdraft reductions with balance infusion.
}

This article is protected by copyright. All rights reserved. 
Rows (5), (6), and (7) decompose the overdraft interest discount effects into the overdraft discount only (row (5)), and the overdraft discount bundled with discounts for autopay (row (6)) or debit card use (row (7)). These results suggest that the overdraft discount by itself does not depress demand to a statistically significant degree (although each of the point estimates is negative); rather, it is the bundled discounts that drive the backfiring effect (see also Table III, columns (3) to (5), rows (2) and (4), which compare bundled discounts to the overdraft discount only). These results support the hypothesis that bundling overdraft discounts with other discounts is particularly demand-depressing. As discussed above, our favored interpretation is that attention to overdraft costs is reactive and associative; we consider alternative interpretations in Section V. ${ }^{15}$

The treatment effects in Table II are likely economically as well as statistically significant, for several reasons. First, they suggest that drawing attention to overdraft costs induces upward-sloping demand, which is rarely seen and hence qualitatively important. Second, the messaging here does not mention the level of costs; instead, YK offers to give back "half of the interest charges." A pure de-biasing strategy would likely mention the price or cost level, along the lines of: "Beware of overdrafts at $60 \%$ APR!" Messaging that highlighted the $60 \%$ APR might depress demand even more, suggesting that we identify a lower bound on the effects of unshrouding overdraft costs. Third, messaging costs are low, and hence bank strategy is sensitive to small changes in demand. Fourth, our estimates identify the effects of sending messages rather than of consumers attending to them. Some

\footnotetext{
${ }^{15}$ Another possible mechanism is directly testable: in Appendix Table AI, Panel B, we do not find any evidence that the automated bill-payment and debit card promotions lead to higher account balances, casting doubt on the possibility that these promotions motivate individuals to maintain larger bank account balances and thereby produce less overdrafting.
}

This article is protected by copyright. All rights reserved. 
recipients may have ignored the messages. This implies that our estimates represent lower bounds for the effects on consumers who actually paid attention to the messages.

\section{B. Do All Promotional Discounts Backfire? No.}

In table III we check whether other promotional discounts backfire as well by estimating treatment effects of the debit card and automated bill-payment discount offers on their targeted behaviors during the experiment. The key results here are presented in columns (1) and (2). In particular, row (1)-column (1) shows that offering the debit discount alone weakly increase debit card usage by 0.5 percentage points $(\mathrm{se}=0.4)$, and row (3)-column (2) estimates that the auto-pay discount alone increases auto-pay signup by 0.4 percentage points $(\mathrm{se}=0.1)$. These effects are each scaled relative to the Overdraft Interest Discount Only message (notice that the omitted category here is different here than in Table II, since here we are primarily interested in whether the other discounts affect demand for their services). ${ }^{16}$ Row (2)-column (1) and row (4)-column (2) test whether bundling a discount with the Overdraft Interest Discount message performs differently, with respect to demand for debit cards and auto-pay, than offering a discount on debit or auto-pay alone. We do not find evidence of differential effects.

In sum, we find no evidence that offering discounts on other bank services backfires with respect to demand for those services, and some evidence that they increase demand as intended.

\footnotetext{
${ }^{16}$ Alternative comparisons, not shown in the table, produce similar inferences. If, for example, we instead estimate effects relative to not getting a debit card discount, the Debit Card Discount Only coefficient for 1/0 debit card usage is 0.0067 ( $\mathrm{se}=0.0039$ ), and the Debit Card Discount + Overdraft Interest Discount coefficient is 0.0059 ( $\mathrm{se}=0.0039)$.
}

This article is protected by copyright. All rights reserved. 


\section{Do Treatment Effects Persist? Post-Experiment Effects of Overdraft Messaging}

Table IV reestimates our main specifications from Table II over the post-promotional campaign period for the two overdraft usage measures for which we have data from January to May 2013. (Recall that the most-intensively treated accountholders in our experiment received their last message on December 15, 2012.) We find no statistically significant evidence that treatment effects persist over the five-month post-experiment period: the overdraft discount effect is no longer demand-depressing, and the overdraft availability effect is no longer demand-increasing. Figure 3, panels A and B, plot the two treatment effects and their confidence intervals month-by-month for our $1 / 0$ measure of overdraft usage. As can be seen, both treatment effects trend toward zero over the post-campaign period and lose statistical significance about two months post-campaign (between February and March).

[FIGURE 3: Effects of Overdraft Availability Message and Overdraft Interest Discount on Overdraft Usage Rate (Panel A and Panel B)] 
Panel A: Effect of Overdraft Availability Message on Overdraft

Usage Rate, Post-Experiment

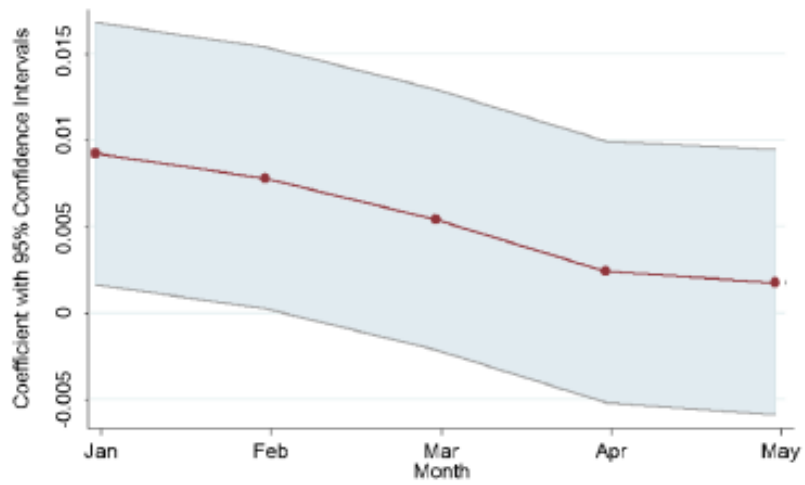

Panel B: Effect of Overdraft Interest Discount on Overdraft Usage Rate, Post-Experiment

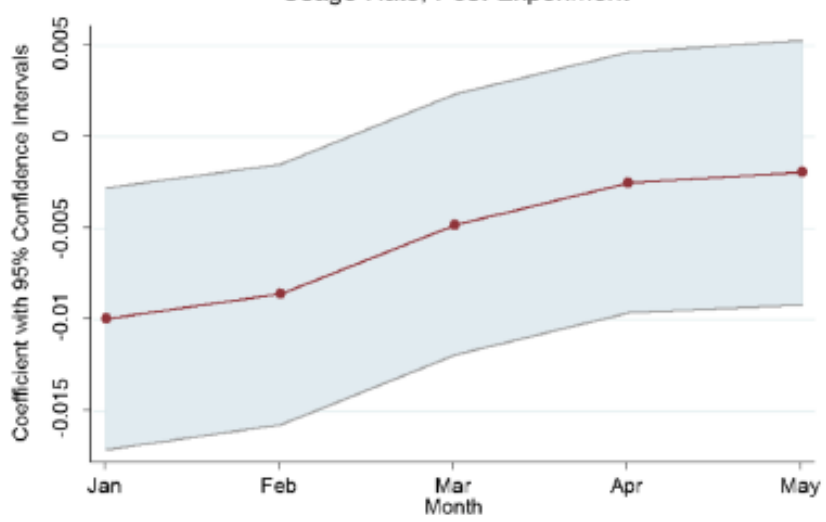

Figure 3. Effects of Overdraft Availability Message and Overdraft Interest Discount on

Overdraft Usage Rate. This figure plots month-by-month treatment effects and associated confidence bands covering the post-experiment period (January to May 2013). Coefficients are estimated using a monthly version of the specification in Table IV, Column (1).

The results in table IV suggest that the overdrafting changes induced by bank promotions are not "sticky": the changes do not persist long after the promotions stop. This could be related to the fact that consumers overdraft passively in the course of checking account usage (rather than explicitly drawing from a line of credit): overdrafts are plausibly low "exposure" and hence relatively likely to be ignored or forgotten (Bordalo, Gennaioli, 
and Shleifer (2015)). In any case, the lack of persistent effects suggests that consumer learning and/or attention concerning overdrafts depreciates quickly, and hence that advertising and de-biasing campaigns must persist to be effective.

\section{Heterogeneous Effects of Overdraft Messaging?}

Our motivating models predict that responses to add-on advertising will vary with how well-informed and/or attentive the consumer is. For example, a well-informed and attentive consumer should exhibit a standard demand response to the overdraft interest discount (increasing, not decreasing, demand) and should respond weakly if at all to the overdraft availability reminder.

We construct two proxies for baseline exposure to the overdraft product and then test whether each proxy mediates our main treatment effects. The first proxy is recent overdraft use prior to the experiment. We find that $18 \%$ of our sample overdrafted at some point during September 2011 to August 2012. Table V interacts a prior use indicator with our main treatment variables and shows little evidence of heterogeneous treatment effects ( $p$-values at the bottom of the table). The second proxy is generated by the August $30^{\text {th }}$ Overdraft Availability message that YK sent to half of the sample. This initial message may have provided some consumers with information and/or drawn their attention to the add-on. But in Appendix Table A III we show that while the point estimate for the interest discount is more negative for those who first received the August $30^{\text {th }}$ Overdraft Availability message, the difference is not statistically significant ( $p$-values at bottom of the table). We caution, however, that the confidence intervals for the heterogeneity results include both null and economically important point estimates. 
We also examine heterogeneity with respect to baseline checking account balances. The intuition is that those with higher account balances may be less responsive to the messages (both availability and discount), as the messages are less relevant for them. As reported in Table VI, we do not find any evidence of heterogeneity in this regard. This could reflect the fact that most accounts, even those with above-median balances at baseline, dip low enough that overdrafting is viable and relevant. (Unfortunately we lack baseline data on minimum balances).

Another interesting margin of heterogeneity concerns the hypothesis that the mostintense overdraft users should be better informed about overdraft costs and more attuned to overdraft availability, in which case both treatment effects should attenuate and even flip sign at high usage. We examine this hypothesis by estimating quantile treatment effects, and do see hints of the expected pattern (Appendix Figure A1). However, we caution that these quantile regressions provide only coarse tests of the relationship between overdraft intensity and demand responses - they are underpowered, and they identify the heterogeneity of interest only with the additional assumption that ordinal position in the overdraft distribution is unaffected by the messages.

\section{E. Other Treatment Variations: Messaging Frequency and Duration}

Appendix Table AIV examines our messaging frequency treatments. We find that more-frequent messaging amplifies the demand-depressing effect of the Overdraft Interest Discount message and the demand-increasing effect of the Overdraft Availability message.

The odd columns in Appendix Table AIV estimate the effect of one-shot versus repeated messaging for the September $15^{\text {th }}$ message. In each treatment, the results are null for the one-shot and strong when the messages are repeated, that is, more negative for the 
discount and more positive for availability. Thus, the results in Table II are driven by repeated messaging, not the one-shot message. Four of the six comparisons between the oneshot and repeated messaging coefficients are statistically different from each other, and none of the six $p$-values is greater than 0.17. The even columns further separate repeated messaging into more- versus less-frequent (every 10 days versus every 20 days messaging), and although the point estimates on more-frequent messaging are larger in absolute value in five of the six comparisons, no difference is statistically significant. The key takeaways from Appendix Table AIV are that one message is not enough to generate an effect, and that repeat messaging influences demand, with diminishing marginal effects from messaging every 10 versus 20 days.

Appendix Table AV examines our other margin of messaging and promotional intensity, namely, the "duration" or length of time, over which the bank continued to send messages and offer discounts. Recall that short-duration campaigns lasted until November $15^{\text {th }}$, while long-duration campaigns continued until December $15^{\text {th }}$. We find little evidence that duration alone affects demand, either for the overdraft interest discount (row (5) versus row (6)), or for the overdraft availability message (row (2) versus row (3)), with the lone exception being the availability messaging effect on overdraft average balance (column (6)).

Promotional intensity depends on duration and frequency, and the even numbered columns in Appendix Table AV shed light on these interactions for the overdraft discount (rows (7) to (10)) and the overdraft availability message (rows (2) to (4)). Comparing, for example, the most intense price promotion (row (7): long duration + messages after September 15) to the least intense promotion (row (10): short duration, no messages after September 15), we find lower demand for the most intense promotion in all three cases, with 
$p$-values on the difference of $0.07,0.08$, and $0.002 .{ }^{17}$ We see a similar pattern of results for overdraft availability marketing, with the point estimate on the most intense promotion (row (2): long duration + messages after September 15) substantially larger than that on the least intense promotion (row (4): September 15 message and no subsequent ones), with $p$-values of $0.07,0.25$, and 0.02 .

All told, we infer that more intense promotions amplify both the demand-increasing effect of the Overdraft Availability message and the demand-depressing effect of the Overdraft Interest Discount message. It could be the case that one message is sufficient to change behavior if noticed, but any one message is noticed with low probability. Alternatively, it could be the case that one message is sufficient to trigger awareness (of a shrouded attribute), but subsequent messages are required to trigger action. This also implies that demand responds more conventionally to less intense overdraft price promotion.

\section{Discussion}

Taken together our results are consistent with models in which consumers have limited and reactive attention to add-ons like overdrafts, and suppliers respond by shrouding add-on costs. Specifically, it seems that overdraft costs and availability are not at the top of consumers' mind, and even when brought closer to top of mind they do not stay there for long. As such, recent behavioral models of add-on pricing, marketing, and usage capture key aspects of reality, with consumers that tend to underestimate add-on costs and react strongly

\footnotetext{
${ }^{17}$ Note that the point estimates on one-shot messaging about the overdraft discount suggest weakly standard/downward-sloping price effects on demand (rows (1) and (5) in Appendix Table AIV, and rows (9) and (10) in Appendix Table AV).
}

This article is protected by copyright. All rights reserved. 
but temporarily when their attention is drawn to add-on, and with firms that lack incentives to unshroud or compete on add-on costs.

Classically rational models can explain at most a subset of our results. In principle, one could rationalize the finding that a large price discount decreases overdraft demand with a wealth effect that is big enough to counteract the standard price effect. In practice, such a wealth effect seems implausible. First, the wealth effect would likely operate among those who actually overdraft and have the most wealth to gain, yet we find effects on the extensive margin. Second, the demand reduction does not persist after the promotions stop, which implies that any wealth effect would have to be transient and begs the question of why, since the overdraft discount is conditional on usage and hence does not alleviate liquidity constraints. Third, a wealth effect should operate through non-overdraft discounts as well, yet we do not find any evidence that debit card or automated bill-payment discounts alone reduce overdrafting. Fourth, a wealth effect does not explain why overdraft availability messaging also affects demand.

Another potential explanation for the overdraft price discount backfiring, particularly in light of Johnson, Meier and Toubia (2015), is that consumers view the offer as "too good to be true", that is, they mistrust YK. But mistrust would not readily explain our other key results on availability and lack of persistence. First, it is silent on why availability increases demand and begs the question of why discount-driven mistrust would dissipate almost immediately after the campaign ends. Second, it is not clear why consumers would mistrust the overdraft interest discount but not other deep discounts that prevail in equilibrium, like "free" checking and teaser rates on credit cards. Third, a mistrust channel need not be distinct from the behavioral mechanisms described above; indeed, Johnson, Meier and Toubia (2015) find that some "households expect there to be hidden fees and cumbersome processes that are 
not compensated by the attractiveness of the offer." Fourth, it is not clear why our sample consumers would respond by decreasing demand for overdrafts rather than simply ignoring the offer: do consumers assume that hidden costs exceed the value of the discount? Fifth, if YK's clients did think that YK was trying to trick them, we might expect them to reduce their demand for other YK services. Yet we find no such evidence (see Appendix Table AII), and the point estimates of the effect of the overdraft discount on the number of active YK accounts are actually positive rather than negative. Sixth, several institutional differences between our experiment and Johnson, Meier and Toubia's (2015) that make mistrust more important in their context. In particular, the offer in Johnson, Meier and Toubia (2015) was too good to be true in the sense of being government-subsidized, and that offer was made by a mortgage servicer at a time when the servicing industry was known to be mistreating and scamming customers (e.g., Consumer Financial Protection Bureau (2013)).

Rational inattention, and/or high search costs a la Ellison (2005), could explain our results, but under assumptions that strike us as antithetical to those sorts of models. For example, instead of remembering new information, consumers quickly forget it. Perhaps more critically, instead of mean-zero but noisy perceptions of costs and credit lines, a rational checking account holder in our setting would need to systematically underestimate them. But does it make sense to think of consumers as rational if they hold biased perceptions of contract terms in equilibrium? Much of behavioral economics answers this question with an emphatic no - indeed, they draw the line between rational versus behavioral based on a distinction between mean-zero versus biased deviations from classical assumptions about decision-making.

Relatedly, one could rationalize the bundled discount results as due to reduced attention costs more broadly, rather than to increased attention to add-on costs in particular, as the key 
factor mediating consumer choices. Specifically, inducing use of auto-pay or debit cards could increase the customer's engagement with the bank, thereby lowering costs of monitoring her cash flows, and reducing overdrafts. ${ }^{18}$ But messages that discount only the bundled products and do not mention overdraft do not reduce overdraft usage. Thus, the mechanism seems unlikely to hinge only on a (rational) increase in attention to the checking account more broadly. Some heightened awareness of add-on costs is likely key.

Notwithstanding the above, we emphasize are not dismissing rational or near-rational explanations for our results. Rather, we are merely speculating that behavioral models of limited attention, memory, and shrouding have great potential to explain the full picture.

\section{Conclusion}

Working with a large Turkish bank to test SMS direct marketing promotions to 108,000 existing checking account holders, we find that messages promoting a $50 \%$ discount on the overdraft interest rate reduce overdraft usage. In contrast, messages that mention overdraft availability without mentioning price increase usage. Neither change persists long, however, after messages stop. We also find some evidence that messaging intensity reinforces the main effects of overdraft discount and availability advertising-messaging more about the overdraft discount further reduces demand, while messaging more about overdraft availability further increases demand - and that messages offering discounts on debit card or auto-pay use along with overdraft backfire more than simply offering a discount on overdrafts. But not all discounts backfire: we find some evidence that debit card and auto-pay discounts increase usage of those features.

\footnotetext{
${ }^{18}$ This is akin to a lower Gabaix and Laibson-type "substitution cost" of avoiding the add-on.
} 
Our results suggest that competing on overdraft prices will not capture market share or increase usage and thus will lower revenue. Although cutting overdraft prices could in principle generate more customer loyalty or reciprocity, the fact that induced overdraft behavior does not persist suggests that these sorts of long-term benefits will not materialize for banks.

More subtly, our results should give pause to third parties seeking to improve overdraft markets with messages (like social marketing campaigns) that draw attention to overdraft costs. To fix ideas, imagine messaging around the theme of "Beware of big overdraft fees!" that is delivered by an entity that might benefit from unshrouding, for example, a regulator, a firm with social objectives or a product-differentiation strategy, or a personal financial management service. Our results are consistent with models of limited and reactive attention formalize the idea that consumer responses to unshrouding are overreactions rather than optimal responses to new information (e.g., Gabaix (2014), Bordalo, Gennaioli, and Shleifer (2015)). Our results further suggest that unshrouding could be quite costly to sustain, since its effects do not persist and that incumbent suppliers could effectively counter unshrouding campaigns by advertising non price attributes (like availability/credit lines in our case). Accordingly, we are sympathetic to Heidhues, Köszegi, and Murooka's (2017) conjecture that third parties, or deviating firms, will be outgunned in a messaging arms race with incumbent add-on suppliers.

Although our results support policymakers' increasing scrutiny of add-on features, pricing, and practices, we emphasize that we do not conduct the sort of welfare analysis that should motivate and guide policy interventions. One reason we stop short of welfare analysis is that we do not actually have the ability to sharply test existing models of shrouded equilibria, since our experiment considers the existing client base of a single firm rather than 
competition for customers across firms (Armstrong and Vickers (2012), Gabaix and Laibson (2006), Grubb (2015), Heidhues, Köszegi, and Murooka (2017)).

Future work would do well to focus on welfare, although doing so may require far more household-level consumption and expenditure data than are typically available in studies that rely on administrative data alone. Refining our design could also help test across models, for instance, by testing promotions that mention price without cutting it and by mentioning information on price levels as well as or instead of discounts. It would also be useful to examine consumer perceptions of add-on prices and expectations of usage more directly, given their centrality to theoretical assumptions and predictions.

Initial submission: [DATE]; Accepted: [DATE CONDITIONALLY ACCEPTED]

Editors: Stefan Nagel, Philip Bond, Amit Seru, and Wei Xiong

\section{REFERENCES}

Agarwal, Sumit, John Driscoll, Xavier Gabaix, and David Laibson, 2013. Learning in the Credit Card Market, NBER working paper No. 13822.

Anagol, Santosh, and Hugh Hoikwang Kim, 2012, The impact of shrouded fees: Evidence from a natural experiment in the Indian mutual funds Market, American Economic Review $102,576-593$.

Armstrong, Mark, and John Vickers, 2012, Consumer protection and contingent charges, Journal of Economic Literature 50, 477-493.

This article is protected by copyright. All rights reserved. 
Ater, Itai, and Vardit Landsman, 2013, Do customers learn from experience? Evidence from retail banking, Management Science 59, 2019-2035.

Bakker, Trevor, Nicole Kelly, Jesse Leary, and Eva Nagypal, 2014, Data point: Checking account overdraft, Data Point, Consumer Financial Protection Bureau.

Banerjee, Abhijit, Dean Karlan, and Jonathan Zinman, 2015, Six randomized evaluations of microcredit: Introduction and further steps, American Economic Journal: Applied Economics $7,1-21$.

Bertrand, Marianne, Dean Karlan, Sendhil Mullainathan, Eldar Shafir, and Jonathan Zinman, 2010, What's advertising content worth? Evidence from a consumer credit marketing field experiment, Quarterly Journal of Economics 125, 263-305.

Bordalo, Pedro, Nicola Gennaioli, and Andrei Shleifer, 2013, Salience and Consumer Choice, Journal of Political Economy 121, 803-843.

Bordalo, Pedro, Nicola Gennaioli, and Andrei Shleifer, 2015, Memory, attention, and choice, NBER Working Paper No. 23256.

Brown, Jennifer, Tanjim Hossain, and John Morgan, 2010, Shrouded attributes and information suppression: Evidence from the field, The Quarterly Journal of Economics 125, $859-876$.

Cadena, Ximena, and Antoinette Schoar, 2011, Remembering to pay? Reminders vs. financial incentives for loan payments, NBER Working Paper No. 17020.

Chetty, Raj, Adam Looney, and Kory Kroft, 2009, Salience and taxation: Theory and evidence, The American Economic Review 99, 1145-1177. 
Competition and Markets Authority, 2014, Personal current accounts: Market study update.

Consumer Financial Protection Bureau, 2013, Supervisory highlights: Winter 2013.

Consumer Financial Protection Bureau v. TCF National Bank, 2017, US District Court of Minnesota.

Dougherty, Carter, 2014, Banks Face Hit from CFPB on \$30 Billion in Overdraft Fees. Bloomberg, July 31.

Eliaz, Kfir, and Ran Spiegler, 2011, Consideration sets and competitive marketing, Review of Economic Studies 78, 235-262.

Elizondo, Alan, and Enrique Seira, 2017, Are information disclosure mandates effective?

Evidence from the credit card market, American Economic Journal: Economic Policy 9, 277307.

Ellison, Glenn, 2005, A model of add-on pricing, Quarterly Journal of Economics 120, 585637.

Ferman, Bruno, 2016, Reading the fine print: Credit demand and information disclosure in Brazil, Management Science 62, 3534-3548.

Financial Conduct Authority, 2014, Consumer Credit Insights: Overdrafts.

Gabaix, Xavier, 2014, A sparsity-based model of bounded rationality, Quarterly Journal of Economics 129, 1661-1710.

Gabaix, Xavier, and David Laibson, 2006, Shrouded attributes, consumer myopia, and information suppression in competitive markets, Quarterly Journal of Economics 121, 505540. 
General Accounting Office, 2008, Bank fees: Federal banking regulators could better ensure that consumers have required disclosure documents prior to opening checking or savings accounts." GAO-08-281.

Gneezy, Uri, and Aldo Rustichini, 2000, A Fine Is a Price, Journal of Legal Studies 29, 1-18.

Grubb, Michael D, 2009, Selling to overconfident consumers, American Economic Review, $1770-1807$.

Grubb, Michael D, 2015, Consumer inattention and bill-shock regulation, Review of Economic Studies 82, 219-57.

Hanna, Rema, Sendhil Mullainathan, and Joshua Schwartzstein, 2014, Learning through noticing: Theory and experimental evidence in farming, Quarterly Journal of Economics 129, $1311-1353$.

Haselhuhn, Michael, Devin Pope, Maurice Schweitzer, and Peter Fishman, 2012, "The impact of personal experience on behavior: Evidence from video-rental Fines, Management Science 58, 35-51.

Hastings, Justine S., and Jesse M. Shapiro, 2013, Fungibility and consumer choice: Evidence from commodity price shocks, Quarterly Journal of Economics 128, 1449-1498.

Heidhues, Paul, Botond Köszegi, and Takeshi Murooka, 2017, Inferior products and profitable deception, Review of Economic Studies 84, 323-356.

Hunt, Stefan, Darragh Kelly, and Fabian Garavito, 2015, Message received? The impact of annual summaries, text alerts and mobile apps on consumer banking behaviour. 
Johnson, Eric, Stephan Meier, and Olivier Toubia, 2015, Money left on the kitchen table: Exploring sluggish mortgage refinancing using administrative data, surveys, and field experiments, working paper, Columbia University.

Kamenica, Emir, 2012, Behavioral economics and psychology of incentives, Annual Review Economics 4, 427-452.

Karlan, Dean, Margaret McConnell, Sendhil Mullainathan, and Jonathan Zinman, 2016, Getting to the top of mind: How reminders increase saving, Management Science 62, 33933411.

Karlan, Dean, Melanie Morten, and Jonathan Zinman, 2015, A personal touch: Text messaging for loan repayment, Behavioral Science \& Policy 1, 25-32.

Karlan, Dean, and Jonathan Zinman, 2010, Expanding credit access: Using randomized supply decisions to estimate the impacts, Review of Financial Studies 23, 433-64.

Kast, Felipe, Stephan Meier, and Dina Pomeranz, 2016, Saving more in groups: Field experimental evidence from Chile, NBER Working Paper No.18417.

Liu, Xiao, Alan Montgomery, and Kannan Srinivasan, 2014, Setting Overdraft Fees in the Presence of Mobile Alerts Using Consumer Financial Transaction Data, Working Paper \#2015-E1.

Manoli, Dayanand S., and Nicholas Turner, 2015, Nudges and learning: Evidence from informational interventions for low-income taxpayers, NBER Working Paper No. 20718.

Schwartzstein, Joshua, 2014, Selective attention and learning, Journal of the European Economic Association 12, 1423-1452. 
Stango, Victor, and Jonathan Zinman, 2014, Limited and varying consumer attention:

Evidence from shocks to the salience of bank overdraft fees, Review of Financial Studies 27,

$990-1030$.

Toksabay, Ece, 2013, Turkish bank shares fall on overdraft interest rate cap, Reuters, May

27.

Zinman, Jonathan. 2014, Consumer credit: Too much or too little (or just right)? Journal of

Legal Studies 43 (S2 Special Issue on Benefit-Cost Analysis of Financial Regulation), S209-

237.

Table I

Baseline Variables for Sample Description and Orthogonality Checks

Columns (1) to (10) report proportions, with standard errors in parentheses. Column (11) reports the $p$-value from the test of the joint hypothesis that the coefficients on the treatment indicators are zero. Variables measured in July 2012 unless noted otherwise. Figure 1 provides details on the treatment arms. *, **, and ${ }^{* * *}$ indicate statistically different from zero at the $10 \%, 5 \%$, and $1 \%$ level of significance, respectively.

\begin{tabular}{|c|c|c|c|c|c|c|c|c|c|c|c|}
\hline & \multirow{4}{*}{$\begin{array}{l}\text { Full } \\
\text { Sample } \\
\text { (1) }\end{array}$} & \multirow{4}{*}{$\begin{array}{c}\text { Got Aug30 } \\
\text { Msg } \\
\text { (2) }\end{array}$} & \multirow{2}{*}{\multicolumn{8}{|c|}{$\begin{array}{c}\text { September } 15 \text { and Subsequent Messages } \\
\end{array}$}} & \multirow{4}{*}{ 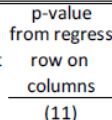 } \\
\hline & & & \multirow[b]{2}{*}{ Any } & \multicolumn{2}{|c|}{ Overdraft Interest Discount } & & & Bill-Pay & \multirow{2}{*}{\multicolumn{2}{|c|}{$\begin{array}{c}\begin{array}{c}\text { Debit Card Discount } \\
\text { Subsequent } \\
\text { Msgs }\end{array} \\
\end{array}$}} & \\
\hline & & & & $\begin{array}{c}\text { Subsequent } \\
\text { Msgs }\end{array}$ & $\begin{array}{l}\text { w/Auto Bill-Pay } \\
\text { Discount }\end{array}$ & \multirow{2}{*}{$\begin{array}{c}\text { w/Debit } \\
\text { Discount } \\
\text { (6) } \\
\end{array}$} & \multicolumn{2}{|c|}{$\begin{array}{c}\text { Subsequent } \\
\text { Msgs }\end{array}$} & & & \\
\hline & & & (3) & (4) & (5) & & (7) & (8) & (9) & (10) & \\
\hline \multirow[t]{2}{*}{ Female } & 0.289 & 0.288 & 0.288 & 0.288 & 0.289 & 0.288 & 0.288 & 0.288 & 0.288 & 0.288 & 1.000 \\
\hline & $(0.001)$ & $(0.002)$ & $(0.002)$ & $(0.002)$ & $(0.003)$ & $(0.003)$ & $(0.003)$ & $(0.004)$ & $(0.003)$ & $(0.004)$ & \\
\hline \multirow[t]{2}{*}{ Lives in Istanbul } & 0.275 & 0.275 & 0.275 & 0.275 & 0.275 & 0.274 & 0.275 & 0.274 & 0.276 & 0.276 & 1.000 \\
\hline & $(0.001)$ & $(0.002)$ & $(0.002)$ & $(0.002)$ & $(0.003)$ & $(0.003)$ & $(0.003)$ & $(0.004)$ & $(0.003)$ & $(0.004)$ & \\
\hline \multirow[t]{2}{*}{ Lives in Ankara } & 0.090 & 0.090 & 0.090 & 0.091 & 0.090 & 0.090 & 0.091 & 0.090 & 0.089 & 0.089 & 1.000 \\
\hline & $(0.001)$ & $(0.001)$ & $(0.001)$ & $(0.002)$ & $(0.002)$ & $(0.002)$ & $(0.002)$ & $(0.003)$ & $(0.002)$ & $(0.003)$ & \\
\hline \multirow[t]{2}{*}{ Lives in Izmir } & 0.050 & 0.050 & 0.050 & 0.050 & 0.050 & 0.050 & 0.050 & 0.050 & 0.050 & 0.051 & 1.000 \\
\hline & $(0.001)$ & $(0.001)$ & $(0.001)$ & $(0.001)$ & $(0.002)$ & $(0.002)$ & $(0.002)$ & $(0.002)$ & $(0.002)$ & $(0.002)$ & \\
\hline \multirow[t]{2}{*}{ Lives in Bursa } & 0.057 & 0.057 & 0.057 & 0.057 & 0.057 & 0.058 & 0.057 & 0.058 & 0.057 & 0.057 & 0.998 \\
\hline & $(0.001)$ & $(0.001)$ & $(0.001)$ & $(0.001)$ & $(0.002)$ & $(0.002)$ & $(0.002)$ & $(0.002)$ & $(0.002)$ & $(0.002)$ & \\
\hline \multirow[t]{2}{*}{ Married } & 0.572 & 0.572 & 0.572 & 0.572 & 0.572 & 0.571 & 0.571 & 0.571 & 0.573 & 0.573 & 1.000 \\
\hline & $(0.002)$ & $(0.002)$ & $(0.002)$ & $(0.003)$ & $(0.004)$ & $(0.004)$ & $(0.004)$ & $(0.005)$ & $(0.004)$ & $(0.005)$ & \\
\hline Overdraft Limit Between & 0.284 & 0.284 & 0.284 & 0.284 & 0.282 & 0.285 & 0.284 & 0.283 & 0.284 & 0.284 & 1.000 \\
\hline $1 / 2$ and 1 monthly min wage & $(0.001)$ & $(0.002)$ & $(0.002)$ & $(0.002)$ & $(0.003)$ & $(0.003)$ & $(0.003)$ & $(0.004)$ & $(0.003)$ & $(0.004)$ & \\
\hline \multirow[t]{2}{*}{ Overdraft Limit > monthly min wage } & 0.081 & 0.081 & 0.081 & 0.081 & 0.081 & 0.080 & 0.082 & 0.082 & 0.082 & 0.082 & 0.999 \\
\hline & $(0.001)$ & $(0.001)$ & $(0.001)$ & $(0.001)$ & $(0.002)$ & $(0.002)$ & $(0.002)$ & $(0.003)$ & $(0.002)$ & $(0.002)$ & \\
\hline \multirow[t]{2}{*}{ Main Acct Bal: Balance below med } & 0.428 & 0.428 & 0.428 & 0.428 & 0.428 & 0.427 & 0.427 & 0.427 & 0.428 & 0.428 & 1.000 \\
\hline & $(0.002)$ & $(0.002)$ & $(0.002)$ & $(0.003)$ & $(0.004)$ & $(0.004)$ & $(0.004)$ & $(0.005)$ & $(0.004)$ & $(0.005)$ & \\
\hline \multirow[t]{2}{*}{ Main Acct Bal: Balance above med } & 0.427 & 0.427 & 0.427 & 0.427 & 0.427 & 0.427 & 0.428 & 0.427 & 0.426 & 0.426 & 1.000 \\
\hline & $(0.002)$ & $(0.002)$ & $(0.002)$ & $(0.003)$ & $(0.004)$ & $(0.004)$ & $(0.004)$ & $(0.005)$ & $(0.004)$ & $(0.005)$ & \\
\hline \multirow[t]{2}{*}{ Used Overdraft Sept 2011-Apr 2012} & 0.184 & 0.185 & 0.184 & 0.184 & 0.184 & 0.183 & 0.179 & 0.180 & 0.189 & 0.188 & 0.502 \\
\hline & $(0.001)$ & $(0.002)$ & $(0.002)$ & $(0.002)$ & $(0.003)$ & $(0.003)$ & $(0.003)$ & $(0.004)$ & $(0.003)$ & $(0.004)$ & \\
\hline Auto Bill-Pay Registered & 0.028 & 0.028 & 0.027 & 0.026 & 0.026 & 0.026 & 0.029 & 0.028 & 0.030 & 0.031 & 0.193 \\
\hline any time Sept 2011-July 2012 & $(0.000)$ & $(0.001)$ & $(0.001)$ & $(0.001)$ & $(0.001)$ & $(0.001)$ & $(0.001)$ & $(0.002)$ & $(0.001)$ & $(0.002)$ & \\
\hline Any Debit Card POS Transactions & 0.334 & 0.333 & 0.335 & 0.336 & 0.331 & 0.340 & 0.328 & 0.327 & 0.339 & 0.339 & 0.309 \\
\hline Sept 2011-July $2012>0$ & $(0.001)$ & $(0.002)$ & $(0.002)$ & $(0.002)$ & $(0.004)$ & $(0.004)$ & $(0.003)$ & $(0.004)$ & $(0.004)$ & $(0.004)$ & \\
\hline Observations & 108000 & 53974 & 53953 & 35989 & 17981 & 17995 & 18021 & 12026 & 17983 & 11985 & \\
\hline
\end{tabular}

This article is protected by copyright. All rights reserved. 
Table II

Effects of Overdraft Marketing on Overdraft Usage During Experiment (September - December 2012) Each column presents treatment effect estimates from a single OLS regression, with Huber-White standard errors, of the usage measure in the column heading on the experimental variables in the rows. Variables in rows (4) to (7) identify the additive effect of one or more of the interest discount arms, that is, they identify the difference in treatment effects between the Overdraft Availability message and the Overdraft Interest Discount message. Usage measures cover September 15 to December 31, 2012. Account balances are in Turkish Lira, where $1 T L=\$ 0.56$ at the start of the experiment. Figure 1 summarizes the experimental design and shows message scripts. Regressions also include controls for randomization strata. The unit of observation is the unit of randomization: a checking account. *, ${ }^{* *}$, and ${ }^{* * *}$ indicate statistically different from zero at the $10 \%, 5 \%$, and $1 \%$ level of

\begin{tabular}{|c|c|c|c|c|c|c|}
\hline \multirow[t]{2}{*}{ LHS variable: } & \multicolumn{2}{|c|}{$\begin{array}{c}\text { Overdraft } \\
\text { Account Used }\end{array}$} & \multicolumn{2}{|c|}{$\begin{array}{c}\text { Days with } \\
\text { Overdraft Balance }\end{array}$} & \multicolumn{2}{|c|}{$\begin{array}{l}\text { Mean(Overdraft } \\
\text { Account Balance) }\end{array}$} \\
\hline & $(1)$ & $(2)$ & (3) & (4) & (5) & $(6)$ \\
\hline \multicolumn{7}{|l|}{ August 30th Message: } \\
\hline \multirow[t]{2}{*}{ (1) Overdraft Availability } & 0.0007 & 0.0007 & $0.0869 * *$ & $0.0869 * *$ & $1.0555^{* *}$ & $1.0554^{* *}$ \\
\hline & $(0.0028)$ & $(0.0028)$ & $(0.0365)$ & $(0.0365)$ & $(0.4701)$ & $(0.4701)$ \\
\hline (2) No Message & Omitted & Omitted & Omitted & Omitted & Omitted & Omitted \\
\hline \multicolumn{7}{|l|}{ September 15 Message: } \\
\hline (3) Overdraft Mention: identifies effect of & $0.0089^{* *}$ & $0.0089 * *$ & $0.1321 * *$ & $0.1321 * *$ & 0.9562 & 0.9562 \\
\hline Overdraft Availability message & $(0.0042)$ & $(0.0042)$ & $(0.0553)$ & $(0.0553)$ & $(0.7029)$ & $(0.7029)$ \\
\hline \multirow[t]{2}{*}{ (4) Overdraft Mention, with Interest Discount } & $-0.0124^{* * *}$ & & $-0.1607^{* * *}$ & & -0.7427 & \\
\hline & $(0.0040)$ & & $(0.0522)$ & & $(0.6718)$ & \\
\hline \multirow[t]{2}{*}{ (5) Overdraft Mention, with Interest Discount only } & & -0.0069 & & -0.0854 & & -0.3382 \\
\hline & & $(0.0049)$ & & $(0.0640)$ & & $(0.8108)$ \\
\hline \multirow[t]{2}{*}{ (6) Overdraft Mention, w/Interest + Auto Bill-Pay Discounts } & & $-0.0137 * * *$ & & $-0.1884 * * *$ & & -1.0909 \\
\hline & & $(0.0049)$ & & $(0.0635)$ & & $(0.8195)$ \\
\hline \multirow[t]{2}{*}{ (7) Overdraft Mention, w/Interest + Debit Card Discounts } & & $-0.0167 * * *$ & & $-0.2083 * * *$ & & -0.7989 \\
\hline & & $(0.0049)$ & & $(0.0632)$ & & $(0.8397)$ \\
\hline (8) No Overdraft Mention = & Omitted & Omitted & Omitted & Omitted & Omitted & Omitted \\
\hline \multicolumn{7}{|l|}{ Auto Bill-Pay Discount Only or Debit Card Discount Only } \\
\hline Mean(LHS) & 0.3077 & 0.3077 & 2.7676 & 2.7676 & 26.8511 & 26.8511 \\
\hline $\mathrm{SD}(\mathrm{LHS})$ & $(0.46)$ & $(0.46)$ & $(6.05)$ & $(6.05)$ & (77.97) & (77.97) \\
\hline Observations & 108000 & 108000 & 108000 & 108000 & 108000 & 108000 \\
\hline
\end{tabular}

Table III

Effects of Auto Bill-Pay and Debit Card Marketing During Experiment (September to December 2012)

Each column presents treatment effect estimates from a single OLS regression, with Huber-White standard errors, of the usage measure in the column heading on the experimental variables in the rows. Variables in rows (2) and (4) identify the additive effect of the overdraft interest discount, that is, they identify the difference in treatment effects between the discount on some other service in row (1) or (3) and that discount bundled with the overdraft interest discount. Usage measures cover September 15 to December 31, 2012. "POS" = point of sale. Account balances are in Turkish Lira, $1 T L=\$ 0.56$ at the start of the experiment. Figure 1 summarizes the experimental design and shows message scripts. Regressions also include controls for randomization strata. The unit of observation is the unit of randomization: a checking account. $*, * *$, and $* * *$ indicate statistically different from zero at the $10 \%, 5 \%$, and $1 \%$ level of significance, respectively.

\begin{tabular}{|c|c|c|c|c|c|}
\hline LHS variable: & $\begin{array}{c}\text { Any Debit Card POS } \\
\text { Transactions }\end{array}$ & $\begin{array}{c}\text { Any Auto Bill-Pay } \\
\text { Registered }\end{array}$ & $\begin{array}{c}\text { Overdraft Account } \\
\text { Used }\end{array}$ & $\begin{array}{c}\text { Days with Overdraft } \\
\text { Balance }\end{array}$ & $\begin{array}{c}\text { Avg Overdraft } \\
\text { Account Balance }\end{array}$ \\
\hline \multicolumn{6}{|l|}{ September 15 Message: } \\
\hline Only, and Overdraft Interest Discount + Debit Discount) & $(0.0040)$ & & $(0.0049)$ & $(0.0635)$ & $(0.7896)$ \\
\hline \multirow[t]{2}{*}{ (2) Debit Card Discount + Overdraft Interest Discount } & -0.0008 & & $-0.0127^{* * *}$ & $-0.1180^{*}$ & -0.1206 \\
\hline & $(0.0049)$ & & $(0.0048)$ & $(0.0627)$ & $(0.8204)$ \\
\hline (3) Auto Bill-Pay Discount (includes both Auto Bill-Pay & & $0.0042^{* * *}$ & -0.0070 & -0.0883 & -0.8953 \\
\hline (4) Auto Bill-Pay Discount + Overdraft Interest Discount & & $(0.0013)$ & $(0.0048)$ & $(0.0629)$ & $(0.8060)$ \\
\hline (5) Sep15 Message: Overdraft Interest Discount only & Omitted & Omitted & Omitted & Omitted & Omitted \\
\hline Controls for Aug30 \& Sep15 Overdraft Availability Only Msgs & yes & yes & yes & yes & yes \\
\hline $\operatorname{Mean}(\mathrm{LHS})$ & 0.3367 & 0.0134 & 0.3077 & 2.7676 & 26.8511 \\
\hline $\mathrm{SD}(\mathrm{LHS})$ & $(0.47)$ & $(0.11)$ & $(0.46)$ & $(6.05)$ & (77.97) \\
\hline Observations & 108000 & 108000 & 108000 & 108000 & 108000 \\
\hline
\end{tabular}


Table IV

\begin{tabular}{|c|c|c|c|c|}
\hline \multicolumn{5}{|c|}{ Effects of Overdraft Marketing on Overdraft Usage After Experiment (January to May 2013) } \\
\hline \multicolumn{5}{|c|}{$\begin{array}{l}\text { Each column presents treatment effect estimates from a single OLS regression, with Huber-White } \\
\text { standard errors, of the usage measure in the column heading on the experimental variables in the } \\
\text { rows. Variables in rows (4) to (7) identify the additive effect of one or more of the interest discount } \\
\text { arms, that is, they identify the difference in treatment effects between the Overdraft Availability } \\
\text { message and the Overdraft Interest Discount message. Usage measures cover January } 1 \text { to May } 31 \text {, } \\
2012 \text {. Account balances are in Turkish Lira, where } 1 \mathrm{TL}=\$ 0.56 \text { at the start of the experiment. Figure } 1 \\
\text { summarizes the experimental design and shows message scripts. Regressions also include controls for } \\
\text { randomization strata. The unit of observation is the unit of randomization: a checking account. *, **, }\end{array}$} \\
\hline \multirow[t]{2}{*}{ LHS variable: } & \multicolumn{2}{|c|}{$\begin{array}{c}\text { Overdraft } \\
\text { Account Used }\end{array}$} & \multicolumn{2}{|c|}{$\begin{array}{l}\text { Mean(Overdraft } \\
\text { Account Balance) }\end{array}$} \\
\hline & (1) & $(2)$ & (3) & $(4)$ \\
\hline \multicolumn{5}{|l|}{ August 30th Message: } \\
\hline (1) Overdraft Availability & & $\begin{array}{l}-0.0004 \\
(0.0029)\end{array}$ & $\begin{array}{c}0.7385 \\
(0.6262)\end{array}$ & $\begin{array}{c}0.7383 \\
(0.6262)\end{array}$ \\
\hline (2) No Message & Omitted & Omitted & Omitted & Omitted \\
\hline \multicolumn{5}{|l|}{ September 15 Message: } \\
\hline $\begin{array}{l}\text { (3) Overdraft Mention: identifies effect of } \\
\text { Overdraft Availability message }\end{array}$ & $\begin{array}{c}0.0055 \\
(0.0044)\end{array}$ & $\begin{array}{c}0.0055 \\
(0.0044)\end{array}$ & $\begin{array}{c}0.0320 \\
(0.9344)\end{array}$ & $\begin{array}{c}0.0320 \\
(0.9344)\end{array}$ \\
\hline (4) Overdraft Mention, with Interest Discount & $\begin{array}{r}-0.0050 \\
(0.0042)\end{array}$ & & $\begin{array}{c}0.1192 \\
(0.8916)\end{array}$ & \\
\hline (5) Overdraft Mention, with Interest Discount only & & $\begin{array}{l}-0.0024 \\
(0.0051)\end{array}$ & & $\begin{array}{c}0.8686 \\
(1.1030)\end{array}$ \\
\hline (6) Overdraft Mention, w/Interest + Auto Bill-Pay Discounts & & $\begin{array}{l}-0.0067 \\
(0.0051)\end{array}$ & & $\begin{array}{r}-0.7063 \\
(1.0724)\end{array}$ \\
\hline (7) Overdraft Mention, w/Interest + Debit Card Discounts & & $\begin{array}{l}-0.0059 \\
(0.0051)\end{array}$ & & $\begin{array}{c}0.1954 \\
(1.1058)\end{array}$ \\
\hline $\begin{array}{l}\text { (8) No Overdraft Mention = } \\
\text { Auto Bill-Pay Discount Only or Debit Card Discount Only }\end{array}$ & Omitted & Omitted & Omitted & Omitted \\
\hline Mean(LHS) & 0.3713 & 0.3713 & 34.0032 & 34.0032 \\
\hline SD(LHS) & $(0.48)$ & $(0.48)$ & (103.98) & (103.98) \\
\hline Observations & 108000 & 108000 & 108000 & 108000 \\
\hline
\end{tabular}

This article is protected by copyright. All rights reserved. 
Table V

Heterogenous Treatment Effects by Prior Use

Each column presents treatment effect estimates from a single OLS regression, with Huber-White standard errors, of the usage measure in the column heading on the experimental variables in the rows. Variables in rows (4) to (11) identify the additive effect of one or more of the interest discount arms, that is, they identify the difference in treatment effects between the Overdraft Availability message and the Overdraft Interest Discount. Overdraft usage measures cover September 15 to December 31, 2012, except for prior use, which is measured 1/0 pre-experiment over September 2011 -April 2012.

Account balances are in Turkish Lira, where $1 \mathrm{TL}=\$ 0.56$ at the start of the experiment. Figure 1 summarizes the experimental design and shows message scripts. Regressions also include controls for randomization strata. The unit of observation is the unit of randomization: a checking account. * **, and ${ }^{* * *}$ indicate statistically different from zero at the $10 \%, 5 \%$, and $1 \%$ level of significance, res pectively.

\begin{tabular}{|c|c|c|c|c|c|c|}
\hline \multirow{2}{*}{$\begin{array}{l}\text { LHS variable: } \\
\text { Measured during experiment: over September 15-December 31, } 2012\end{array}$} & \multirow{2}{*}{\multicolumn{2}{|c|}{$\begin{array}{c}\text { Overdraft } \\
\text { Account Used }\end{array}$}} & \multirow{2}{*}{\multicolumn{2}{|c|}{$\begin{array}{c}\text { Days with } \\
\text { Overdraft Balance }\end{array}$}} & \multicolumn{2}{|c|}{$\begin{array}{c}\text { Mean(Overdraft } \\
\text { Account Balance) }\end{array}$} \\
\hline & & & & & $\frac{\text { Account }}{(5)}$ & $\frac{\text { Balance) }}{(6)}$ \\
\hline \multirow[t]{2}{*}{ (1) Prior Overdraft Use } & $0.3201^{* * * *}$ & $0.3201^{* * * *}$ & $4.0976^{* * *}$ & $4.0976 * * *$ & $41.6837^{* * *}$ & $41.6835^{* *}$ \\
\hline & $(0.0067)$ & $(0.0067)$ & $(0.1093)$ & $(0.1093)$ & $(1.5148)$ & $(1.5148)$ \\
\hline No Overdraft Use September 2011-April 2012 & Omitted & Omitted & Omitted & Omitted & Omitted & Omitted \\
\hline
\end{tabular}
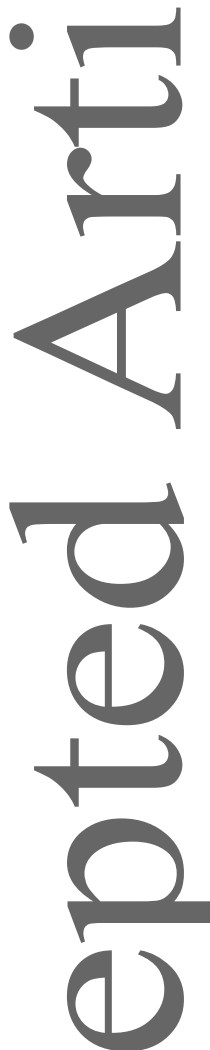

September 15th Message:

(2) Overdraft Mention * Prior Overdraft Use

(3) Overdraft Mention * No Prior Overdraft Use

(4) Overdraft Mention, with Interest Discount * Prior Overdraft Use

(5) Overdraft Mention, with Interest Discount * No Prior Overdraft Use

(6) Overdraft Interest Discount, No Other Discount * Prior Overdraft Use

(7) Overdraft Interest Discount, No Other Discount * No Prior Overdraft Use

(8) Overdraft Interest Discount + Auto Bill-Pay Discount * Prior Overdraft Use

(9) Overdraft Interest Discount + Auto Bill-Pay Discount * No Prior Overdraft Use

(10) Overdraft Interest Discount + Debit Card Discount * Prior Overdraft Use

(11) Overdraft Interest Discount + Debit Card Discount * No Prior Overdraft Use

No Overdraft Mention = Auto Bill-Pay Discount Only or Debit Card Discount Only p-value on F-test of equality between rows (2) and (3) p-value on F-test of equality between rows (4) and (5) p-value on F-test of equality between rows (6) and (7)

p-value on F-test of equality between rows (8) and (9)

p-value on F-test of equality between rows (10) and (11) Mean(LHS)

$\mathrm{SD}$ (LHS)

Observations

\begin{tabular}{|c|c|c|c|c|c|}
\hline $0.0193^{*}$ & $0.0193^{*}$ & 0.2546 & 0.2546 & 0.5915 & 0.5920 \\
\hline$(0.0107)$ & $(0.0107)$ & $(0.1807)$ & $(0.1807)$ & $(2.5326)$ & $(2.5326)$ \\
\hline 0.0055 & 0.0055 & $0.0912^{*}$ & $0.0912^{*}$ & 0.8841 & 0.8843 \\
\hline$(0.0044)$ & $(0.0044)$ & $(0.0521)$ & $(0.0521)$ & $(0.6385)$ & $(0.6385)$ \\
\hline$-0.0205^{* *}$ & & -0.2640 & & 0.4073 & \\
\hline$(0.0101)$ & & $(0.1703)$ & & $(2.3965)$ & \\
\hline$-0.0094^{* *}$ & & $-0.1223^{* *}$ & & -0.8171 & \\
\hline$(0.0041)$ & & $(0.0492)$ & & $(0.6130)$ & \\
\hline & -0.0176 & & -0.1611 & & 1.1800 \\
\hline & $(0.0124)$ & & $(0.2097)$ & & $(2.9235)$ \\
\hline & -0.0036 & & -0.0559 & & -0.5237 \\
\hline & $(0.0051)$ & & $(0.0603)$ & & $(0.7335)$ \\
\hline & -0.0204 & & $-0.3532^{*}$ & & -1.6837 \\
\hline & $(0.0124)$ & & $(0.2093)$ & & $(2.9142)$ \\
\hline & $-0.0109^{* *}$ & & $-0.1362^{* *}$ & & -0.7935 \\
\hline & $(0.0050)$ & & $(0.0598)$ & & $(0.7550)$ \\
\hline & $-0.0236^{*}$ & & -0.2784 & & 1.7192 \\
\hline & $(0.0124)$ & & $(0.2093)$ & & $(3.0806)$ \\
\hline & $-0.0137^{* * *}$ & & $-0.1745^{* * *}$ & & -1.1335 \\
\hline & $(0.0050)$ & & $(0.0592)$ & & $(0.7528)$ \\
\hline Omitted & Omitted & Omitted & Omitted & Omitted & Omitted \\
\hline 0.2348 & 0.2348 & 0.3852 & 0.3851 & 0.9108 & 0.9109 \\
\hline \multirow[t]{4}{*}{0.3068} & & 0.4239 & & 0.6203 & \\
\hline & 0.2952 & & 0.6297 & & 0.5716 \\
\hline & 0.4793 & & 0.3190 & & 0.7675 \\
\hline & 0.4578 & & 0.6330 & & 0.3678 \\
\hline 0.3077 & 0.3077 & 2.7676 & 2.7676 & 26.8511 & 26.8511 \\
\hline$(0.46)$ & $(0.46)$ & $(6.05)$ & $(6.05)$ & (77.97) & (77.97) \\
\hline 108000 & 108000 & 108000 & 108000 & 108000 & 108000 \\
\hline
\end{tabular}


Table VI

Heterogenous Treatment Effects by Baseline Account Balance

Each column presents treatment effect estimates from a single OLS regression, with Huber-White standard errors, of the usage measure in the column heading on the experimental variables in the rows. Variables in rows (2) to (11) identify the effect of one of the interest discount arms interacted with the baseline account balance. Usage measures cover September 15 to December 31, 2012. Account balances are in Turkish Lira, where $1 \mathrm{TL}=\$ 0.56$ at the start of the experiment. Figure 1 summarizes the experimental design and shows message scripts. Regressions also include controls for randomization strata. The unit of observation is the unit of randomization: a checking account. *, $* *$, and *** indicate statistically different from zero at the $10 \%, 5 \%$, and $1 \%$ level of significance, respectively.

\begin{tabular}{l} 
LHS variable: \\
\hline Overdraft Account Used \\
(1) Baseline Account Balance Above Median \\
(2) Sep15 Message: Overdraft Mention * Baseline \\
Acct Bal Above Median
\end{tabular}

Acct Bal Above Median

(3) Sep15 Message: Overdraft Mention * Baseline Acct Bal Below Median

\begin{tabular}{cl}
\multicolumn{2}{c}{ Overdraft } \\
\hline \multicolumn{1}{c}{$(1)$} & \multicolumn{1}{c}{$(2)$} \\
\hline 0.0112 & 0.0113 \\
$(0.0071)$ & $(0.0071)$
\end{tabular}

$\begin{array}{ll}0.0107^{*} & 0.0107^{*} \\ (0.0059) & (0.0059)\end{array}$

$0.0082 \quad 0.0082$ $(0.0060) \quad(0.0060)$

\begin{tabular}{lllll}
\hline \multicolumn{2}{c}{ Days with } & & \multicolumn{2}{c}{ Avg Overdraft } \\
\cline { 5 - 6 }$(3)$ & \multicolumn{1}{c}{$(4)$} & & \multicolumn{1}{c}{$(5)$} & \multicolumn{1}{c}{$(6)$} \\
\hline$-0.2678^{* * *}-0.2674^{* * *}$ & -1.6892 & -1.6870 \\
$(0.0926)$ & $(0.0926)$ & & $(1.1565)$ & $(1.1565)$ \\
& & & & \\
$0.1244^{*}$ & $0.1244^{*}$ & & 0.8753 & 0.8752 \\
$(0.0692)$ & $(0.0692)$ & & $(0.9368)$ & $(0.9368)$ \\
& & & & \\
$0.1573^{*}$ & $0.1573^{*}$ & & 0.9519 & 0.9519 \\
$(0.0861)$ & $(0.0861)$ & $(1.0263)$ & $(1.0263)$
\end{tabular}

$-0.1219^{*}$

(0.0655)

$-0.6248$

(0.8936)
$-0.2070 * *$

(0.0812)
$-0.6918$

(0.9825)

(6) Sep15 Message: Overdraft Interest Discount; No Other Discount* Baseline Acct Bal Above Median

(7) Sep15 Message: Overdraft Interest Discount; No Other Discount* Baseline Acct Bal Below Median

(8) Sep15 Message: Overdraft Interest Discount; Auto Debit Discount * Baseline Acct Bal Above Median

(9) Sep15 Message: Overdraft Interest Discount; Auto Debit Discount * Baseline Acct Bal Below Median

(10) Sep15 Message: Overdraft Interest Discount; Debit Card Discount * Baseline Acct Bal Above Median

(11) Sep15 Message: Overdraft Interest Discount; Debit Card Discount * Baseline Acct Bal Below Median

p-value on F-test of equality between rows (2) and (3)

p-value on F-test of equality between rows (4) and (5)

p-value on F-test of equality between rows (6) and (7)

p-value on F-test of equality between rows ( 8 ) and (9)

p-value on F-test of equality between rows (10) and (11)

Mean(LHS) Sept-Nov

$-0.0117 *$

(0.0057)

$-0.0095$

(0.0069)

$-0.0695$

(0.0803)

0.3711

$-0.0053$

(0.0070)

$-0.1199$

(0.0996)

$-0.3425$

(1.1917)

$-0.0129^{*}$

(0.0069)

$-0.1216$

$-0.5927$

(1.0773)

$-0.0151^{* *}$

(0.0069)

$-0.2608 * * *$

(0.0985)

$-1.2366$

(1.2193)

$-0.0189 * *$.

$-0.1742 *$

(0.0791)

$-0.9077$

(0.0068)

$-0.2401^{* *}$

$-0.0145 *$.

(0.0986)

(1.1189)

$(0.0070)$

$0.7714 \quad 0.7714$

0.7661

0.7661

0.9561

(1.2285)

0.7897

0.4151

0.9598

0.6683

0.6939

0.9858

0.6923

0. 8172

0.2727

0.8026

0.6509

0.3077

0.6024

$2.7676 \quad 2.7676$

$\begin{array}{llllll}(0.46) & (0.46) & (6.05) & (6.05) & (77.97) & (77.97)\end{array}$

26.8511 26.8511

Observations

107337

\section{Appendix: Additional Results}

[FIGURE AI: Distribution of Effect of Overdraft Mention and of Interest Discount]

This article is protected by copyright. All rights reserved. 
Panel A: Distribution of Effect of Overdraft Mention

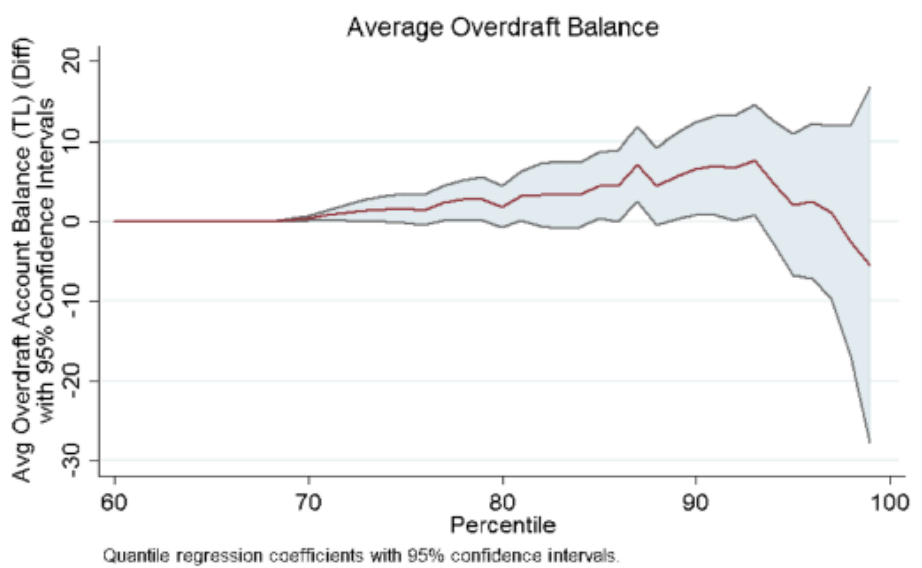

Panel B: Distribution of Effect of Interest Discount, Controlling for Other Overdraft Messages

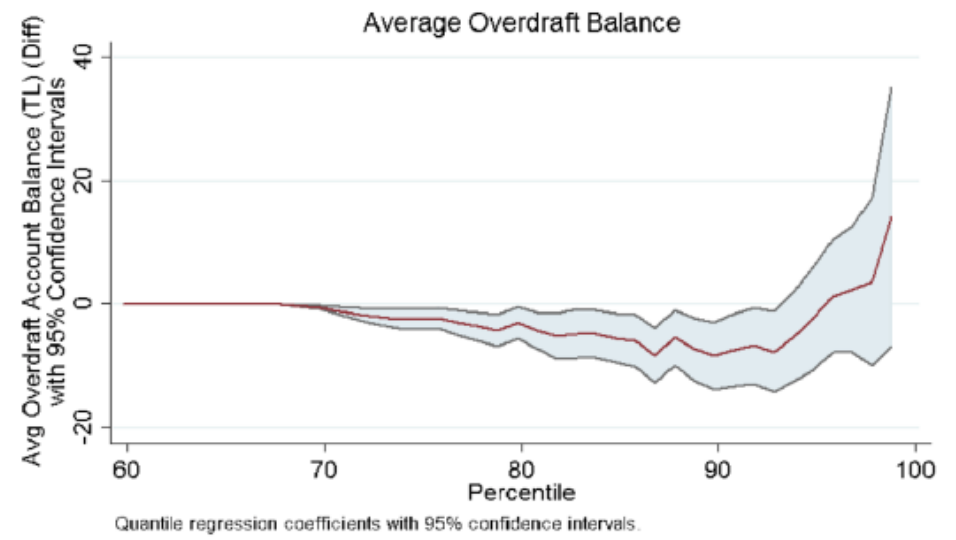

Figure A1. Distribution of Effect of Overdraft Mention and of Interest Discount. Panel A plots the marginal effects of a message mentioning the overdraft account on each quantile of overdraft account balance. Panel B plots the average marginal effects of an interest discount on each quantile of overdraft account balance. 
Table Al

Effects of Marketing on Average Monthly Checking + Savings Balances During Experiment (September to December 2012) Each column-panel presents treatment effect estimates from a single OLS regression, with Huber-White standard errors, of the average balances measure in the column heading on the experimental variables in the rows. Variables in Panel A rows (4) to (7) identify the additive effect of one or more of the interest discount arms, that is, they identify the difference in treatment effects between the Overdraft Availability message and the Overdraft Interest Discount message. Variables in Panel B rows (2) and (4) identify the additive effect of the overdraft interest discount; i.e., they identify the difference in treatment effects between the discount on some other service in row 1 or 3 and that discount bundled with the overdraft interest discount. Balance measures cover September 15 to December 31, 2012. Account balances are in Turkish Lira, where $1 T L=\$ 0.56$ at the start of the experiment. Figure 1 summarizes the experimental design and shows message scripts. Regressions also include controls for randomization strata. The unit of observation is the unit of randomization: a checking account. ${ }^{*}, * *$, and $* * *$ indicate statistically different from zero at the $10 \%, 5 \%$, and $1 \%$ level of significance, respectively. LHS variable: $\quad$ Average Balances Top 1\% Winsorized Top 1\% Dropped L L

\begin{tabular}{|c|c|c|c|c|c|c|c|c|}
\hline \multirow[t]{2}{*}{ LHS variable: } & \multicolumn{2}{|c|}{ Average Balances } & \multicolumn{2}{|c|}{ Top $1 \%$ Winsorized } & \multicolumn{2}{|c|}{ Top $1 \%$ Dropped } & \multicolumn{2}{|c|}{$\log$} \\
\hline & (1) & (2) & (3) & (4) & (5) & $(6)$ & (7) & $(8)$ \\
\hline \multicolumn{9}{|c|}{ Panel A. Overdraft Marketing } \\
\hline \multicolumn{9}{|l|}{ August 30th Message: } \\
\hline \multirow[t]{2}{*}{ (1) Overdraft Availability } & -8.8782 & -8.8742 & $-8.5687^{*}$ & $-8.5665^{*}$ & $-7.3419^{*}$ & $-7.3425^{*}$ & -0.0118 & -0.0118 \\
\hline & $(9.7697)$ & $(9.7695)$ & $(4.9102)$ & $(4.9100)$ & $(3.7965)$ & $(3.7965)$ & $(0.0115)$ & $(0.0115)$ \\
\hline (2) No Message & Omitted & Omitted & Omitted & Omitted & Omitted & Omitted & Omitted & Omitted \\
\hline \multicolumn{9}{|l|}{ September 15 Message: } \\
\hline (3) Overdraft Mention: identifies effect of & -3.5914 & -3.5934 & 2.5982 & 2.5969 & 3.9231 & 3.9228 & -0.0082 & -0.0082 \\
\hline Overdraft Availability message & $(13.9764)$ & $(13.9766)$ & $(7.3735)$ & $(7.3736)$ & $(5.7159)$ & $(5.7159)$ & $(0.0171)$ & $(0.0171)$ \\
\hline \multirow[t]{2}{*}{ (4) Overdraft Mention, with Interest Discount } & 11.4448 & & 3.0329 & & 1.9943 & & 0.0108 & \\
\hline & (12.2665) & & (6.9651) & & $(5.4186)$ & & $(0.0162)$ & \\
\hline \multirow[t]{2}{*}{ (5) Overdraft Mention, with Interest Discount only } & & 24.3365 & & 12.3639 & & 8.0409 & & 0.0237 \\
\hline & & (15.6249) & & $(8.6572)$ & & $(6.7305)$ & & (0.0199) \\
\hline \multirow[t]{2}{*}{ (6) Overdraft Mention, w/Interest + Auto Bill-Pay Discounts } & & 19.7938 & & 7.1275 & & 0.7018 & & 0.0047 \\
\hline & & $(15.7186)$ & & $(8.5911)$ & & $(6.5985)$ & & $(0.0199)$ \\
\hline \multirow[t]{2}{*}{ (7) Overdraft Mention, w/Interest + Debit Card Discounts } & & -9.7688 & & -10.3752 & & -2.7430 & & 0.0042 \\
\hline & & (14.9912) & & $(8.3311)$ & & $(6.5513)$ & & (0.0197) \\
\hline (8) No Overdraft Mention = & Omitted & Omitted & Omitted & Omitted & Omitted & Omitted & Omitted & Omitted \\
\hline \multicolumn{9}{|l|}{ Auto Bill-Pay Discount Only or Debit Card Discount Only } \\
\hline Mean(LHS) & 415.3350 & 415.3350 & 359.4495 & 359.4495 & 305.0098 & 305.0098 & 4.2853 & 4.2853 \\
\hline SD(LHS) & $(1631.25)$ & $(1631.25)$ & $(847.06)$ & $(847.06)$ & (654.51) & $(654.51)$ & $(2.11)$ & (2.11) \\
\hline Observations & 108000 & 108000 & 108000 & 108000 & 106920 & 106920 & 106020 & 106020 \\
\hline
\end{tabular}

\begin{tabular}{|c|c|c|c|c|}
\hline \multicolumn{5}{|c|}{ Panel B. Auto Bill-Pay and Debit Card Marketing } \\
\hline September 15 Message: & & & & \\
\hline $\begin{array}{l}\text { (1) Debit Card Discount (includes both Debit Card Discount Only, } \\
\text { and Overdraft Interest Discount + Debit Discount) }\end{array}$ & $\begin{array}{l}-13.0974 \\
(13.5978)\end{array}$ & $\begin{array}{l}-10.2527 \\
(7.4184)\end{array}$ & $\begin{array}{l}-12.8017^{* *} \\
(5.6403)\end{array}$ & $\begin{array}{l}-0.0213 \\
(0.0172)\end{array}$ \\
\hline (2) Debit Card Discount + Overdraft Interest Discount & $\begin{array}{c}-8.8192 \\
(15.5592)\end{array}$ & $\begin{array}{r}-6.2956 \\
(8.3217)\end{array}$ & $\begin{array}{c}6.0471 \\
(6.4248)\end{array}$ & $\begin{array}{r}0.0137 \\
(0.0198)\end{array}$ \\
\hline (3) Auto Bill-Pay Discount (includes both Auto Bill-Pay Discount & -4.0234 & -7.2920 & -3.0861 & 0.0140 \\
\hline Only, and Overdraft Interest Discount + Auto Bill-Pay Discount) & $(17.0081)$ & (7.3615) & $(5.7486)$ & $(0.0172)$ \\
\hline (4) Auto Bill-Pay Discount + Overdraft Interest Discount & $\begin{array}{c}11.6737 \\
(19.2085)\end{array}$ & $\begin{array}{c}8.2507 \\
(8.5362)\end{array}$ & $\begin{array}{r}-0.2214 \\
(6.5709)\end{array}$ & $\begin{array}{l}-0.0211 \\
(0.0199)\end{array}$ \\
\hline (5) Overdraft Interest Discount only & Omitted & Omitted & Omitted & Omittec \\
\hline Controls for Aug 30 \& Sep 15 Overdraft Availability Only Messages & yes & yes & yes & yes \\
\hline Mean(LHS) & 415.3350 & 359.4495 & 305.0098 & 4.2853 \\
\hline SD(LHS) & $(1631.25)$ & $(847.06)$ & $(654.51)$ & $(2.11)$ \\
\hline Observations & 108000 & 108000 & 106920 & 106020 \\
\hline
\end{tabular}


Table All

Effects of Overdraft Marketing on Number of Active Products During Experiment (September to December 2012)

Each column presents treatment effect estimates from a single OLS regression, with Huber-White standard errors, of the measure of the account holder's active products at the experimenting bank (including the checking account that is our unit of observation) in the column heading on the experimental variables in the rows. Variables in rows (4) to (7) identify the additive effect of one or more of the interest discount arms, that is, they identify the difference in treatment effects between the Overdraft Availability message and the Overdraft Interest Discount message. Figure 1 summarizes the experimental design and shows message scripts. Regressions also include controls for randomization strata. The Unit of observation is the unit of randomization: a checking account. *, ${ }^{* *}$, and ${ }^{* * *}$ indicate statistically different from zero at the $10 \%, 5 \%$, and $1 \%$ level of significance, respectively.

\begin{tabular}{|c|c|c|c|c|}
\hline \multirow[t]{2}{*}{ LHS variable: } & \multicolumn{2}{|c|}{ Count } & \multicolumn{2}{|c|}{$\log$} \\
\hline & (1) & $(2)$ & (3) & (4) \\
\hline \multicolumn{5}{|l|}{ August 30th Message: } \\
\hline \multirow[t]{2}{*}{ (1) Overdraft Availability } & 0.0131 & 0.0131 & 0.0028 & 0.0028 \\
\hline & $(0.0136)$ & $(0.0136)$ & $(0.0047)$ & $(0.0047)$ \\
\hline (2) No Message & Omitted & Omitted & Omitted & Omitted \\
\hline \multicolumn{5}{|l|}{ September 15 Message: } \\
\hline (3) Overdraft Mention: identifies effect of & -0.0002 & -0.0002 & -0.0005 & -0.0005 \\
\hline Overdraft Availability message & $(0.0204)$ & $(0.0204)$ & $(0.0070)$ & $(0.0070)$ \\
\hline \multirow[t]{2}{*}{ (4) Overdraft Mention, with Interest Discount } & 0.0155 & & 0.0093 & \\
\hline & $(0.0192)$ & & $(0.0066)$ & \\
\hline \multirow[t]{2}{*}{ (5) Overdraft Mention, with Interest Discount only } & & 0.0145 & & 0.0074 \\
\hline & & $(0.0235)$ & & $(0.0081)$ \\
\hline \multirow[t]{2}{*}{ (6) Overdraft Mention, w/Interest + Auto Bill-Pay Discounts } & & -0.0073 & & 0.0027 \\
\hline & & $(0.0234)$ & & $(0.0081)$ \\
\hline \multirow[t]{2}{*}{ (7) Overdraft Mention, w/Interest + Debit Card Discounts } & & $0.0393^{*}$ & & $0.0177^{* *}$ \\
\hline & & $(0.0236)$ & & $(0.0081)$ \\
\hline (8) No Overdraft Mention = & Omitted & Omitted & Omitted & Omitted \\
\hline \multicolumn{5}{|l|}{ Auto Bill-Pay Discount Only or Debit Card Discount Only } \\
\hline Mean(LHS) & 2.6238 & 2.6238 & 0.6348 & 0.6348 \\
\hline $\mathrm{SD}$ (LHS) & $(2.27)$ & $(2.27)$ & $(0.78)$ & $(0.78)$ \\
\hline Observations & 108000 & 108000 & 108000 & 108000 \\
\hline
\end{tabular}

This article is protected by copyright. All rights reserved. 
Table AllI

Does the August 30 Message Mediate Treatment Effects of Later Messages?

Each column presents treatment effect estimates from a single OLS regression, with Huber-White standard errors, of the usage measure in the column heading on the experimental variables in the rows. Variables in rows (4) to (11) identify the additive effect of one or more of the interest discount arms, this is, they identify the difference in treatment effects between the Overdraft Availability message and the Overdraft Interest Discount. Overdraft usage measures cover September 15 to December 31, 2012. Account balances are in Turkish Lira, where $1 \mathrm{TL}=\$ 0.56$ at the start of the experiment. Figure 1 summarizes the experimental design and shows message scripts. Regressions also include controls for randomization strata. The unit of observation is the unit of randomization: a checking account. ${ }^{*}, * *$, and ${ }^{* *}$ indicate statistically different from zero at the $10 \%, 5 \%$, and $1 \%$ level of significance,

\begin{tabular}{|c|c|c|c|c|c|c|}
\hline \multirow[t]{2}{*}{$\begin{array}{l}\text { LHS variable: } \\
\text { Measured during experiment: over September 15-December 31, } 2012\end{array}$} & \multicolumn{2}{|c|}{$\begin{array}{c}\text { Overdraft } \\
\text { Account Used }\end{array}$} & \multicolumn{2}{|c|}{$\begin{array}{c}\text { Days with } \\
\text { Overdraft Balance }\end{array}$} & \multicolumn{2}{|c|}{$\begin{array}{l}\text { Mean(Overdraft } \\
\text { Account Balance) }\end{array}$} \\
\hline & $(1)$ & (2) & $(3)$ & (4) & (5) & $(6)$ \\
\hline \multicolumn{7}{|l|}{ August 30th Message: } \\
\hline \multirow[t]{2}{*}{ (1) Overdraft Availability } & -0.0001 & -0.0001 & 0.0477 & 0.0476 & 1.1445 & 1.1444 \\
\hline & $(0.0049)$ & $(0.0049)$ & $(0.0631)$ & $(0.0631)$ & $(0.7875)$ & $(0.7875)$ \\
\hline No message & Omitted & Omitted & Omitted & Omitted & Omitted & Omitted \\
\hline \multicolumn{7}{|l|}{ September 15 Message: } \\
\hline \multirow[t]{2}{*}{ (2) Overdraft Mention with Aug 30 Msg } & $0.0114^{*}$ & $0.0114^{*}$ & $0.2021^{* *}$ & $0.2021^{\bullet \bullet}$ & 0.7911 & 0.7912 \\
\hline & $(0.0060)$ & $(0.0060)$ & $(0.0797)$ & $(0.0797)$ & (1.0046) & $(1.0046)$ \\
\hline \multirow[t]{2}{*}{ (3) Overdraft Mention without Aug $30 \mathrm{Msg}$} & 0.0063 & 0.0063 & 0.0622 & 0.0622 & 1.1209 & 1.1212 \\
\hline & $(0.0060)$ & $(0.0060)$ & $(0.0767)$ & $(0.0767)$ & $(0.9814)$ & (0.9815) \\
\hline \multirow[t]{2}{*}{ (4) Overdraft Mention, with Interest Discount, with Aug $30 \mathrm{Msg}$} & $-0.0151 \cdots$ & & $-0.2149 \bullet *$ & & -0.6116 & \\
\hline & $(0.0056)$ & & $(0.0755)$ & & (0.9576) & \\
\hline \multirow[t]{2}{*}{ (5) Overdraft Mention, with Interest Discount, w/o Aug 30 Msg } & $-0.0098^{*}$ & & -0.1067 & & -0.8735 & \\
\hline & $(0.0056)$ & & $(0.0722)$ & & $(0.9420)$ & \\
\hline \multirow[t]{2}{*}{ (6) Overdraft Interest Discount, No Other Discount, with Aug $30 \mathrm{Msg}$} & & -0.0082 & & $-0.1819 * *$ & & -0.9928 \\
\hline & & $(0.0069)$ & & $(0.0916)$ & & $(1.1290)$ \\
\hline \multirow[t]{2}{*}{ (7) Overdraft Interest Discount, No Other Discount, w/o Aug $30 \mathrm{Msg}$} & & -0.0056 & & 0.0109 & & 0.3160 \\
\hline & & $(0.0069)$ & & $(0.0895)$ & & $(1.1630)$ \\
\hline \multirow[t]{2}{*}{ (8) Overdraft Interest Discount + Auto Bill-Pay Discount, w/Aug 30 Msg } & & $-0.0135^{*}$ & & $-0.1894^{* *}$ & & 0.0209 \\
\hline & & $(0.0069)$ & & $(0.0922)$ & & (1.1848) \\
\hline \multirow[t]{2}{*}{ (9) Overdraft Interest Discount + Auto Bill-Pay Discount, w/o Aug 30 Msg } & & $-0.0139^{* *}$ & & $-0.1875^{* *}$ & & $-2.2005^{*}$ \\
\hline & & $(0.0069)$ & & $(0.0875)$ & & $(1.1330)$ \\
\hline \multirow[t]{2}{*}{ (10) Overdraft Interest Discount + Debit Card Discount, with Aug 30 Msg } & & $-0.0236^{* * *}$ & & $-0.2734 * * *$ & & -0.8622 \\
\hline & & $(0.0069)$ & & $(0.0911)$ & & $(1.2162)$ \\
\hline \multirow[t]{2}{*}{ (11) Overdraft Interest Discount + Debit Card Discount, w/o Aug 30 Msg } & & -0.0098 & & -0.1434 & & -0.7351 \\
\hline & & $(0.0069)$ & & $(0.0877)$ & & (1.1541) \\
\hline No Overdraft Mention = Auto Bill-Pay Discount Only or Debit Card Discount Only & Omitted & Omitted & Omitted & Omitted & Omitted & Omitted \\
\hline p-value on F-test of equality between rows (2) and (3) & 0.5475 & 0.5477 & 0.2058 & 0.2058 & 0.8142 & 0.8140 \\
\hline p-value on F-test of equality between rows (4) and (5) & 0.5031 & & 0.2999 & & 0.8454 & \\
\hline p-value on F-test of equality between rows (6) and (7) & & 0.7870 & & 0.1323 & & 0.4192 \\
\hline p-value on F-test of equality between rows ( 8 ) and (9) & & 0.9644 & & 0.9875 & & 0.1755 \\
\hline p-value on F-test of equality between rows (10) and (11) & & 0.1556 & & 0.3038 & & 0.9395 \\
\hline Mean(LHS) & 0.3077 & 0.3077 & 2.7676 & 2.7676 & 26.8511 & 26.8511 \\
\hline SD(LHS) & $(0.46)$ & $(0.46)$ & $(6.05)$ & $(6.05)$ & $(77.97)$ & (77.97) \\
\hline Observations & 108000 & 108000 & 108000 & 108000 & 108000 & 108000 \\
\hline
\end{tabular}


Table AV

Effects of Overdraft Message and Discount Duration on Overdraft Usage During Experiment (September to December 2012) Each column presents treatment effect estimates from a single OLS regression, with Huber-White standard errors, of the usage measure in the column heading on the experimental variables in the rows. Variables in rows (5) to (10) identify the additive effect of one or more of the interest discount arms; i.e., they identify the difference in treatment effects between the Overdraft Availability message and the Overdraft Interest Discount message. Usage measures cover September 15 to December 31, 2012. Account balances are in Turkish Lira, where $1 \mathrm{TL}=\$ 0.56$ at the start of the experiment. Figure 1 summarizes the experimental design and shows message scripts. Regressions also include controls for randomization strata. The unit of observation is the unit of randomization: a checking account. *, **, and *** indicate statistically different from zero at the $10 \%, 5 \%$, and $1 \%$ level of significance, respectively.

\begin{tabular}{|c|c|c|c|c|c|c|}
\hline \multirow[t]{2}{*}{ LHS variable: } & \multicolumn{2}{|c|}{$\begin{array}{c}\text { Overdraft } \\
\text { Account Used }\end{array}$} & \multicolumn{2}{|c|}{$\begin{array}{c}\text { Days with } \\
\text { Overdraft Balance }\end{array}$} & \multicolumn{2}{|c|}{$\begin{array}{l}\text { Mean(Overdraft } \\
\text { Account Balance) }\end{array}$} \\
\hline & (1) & (2) & (3) & (4) & $(5)$ & (6) \\
\hline \multicolumn{7}{|l|}{ September 15 Message: } \\
\hline (1) Overdraft Mention: identifies effect of Overdraft Availability Message & $\begin{array}{l}0.0089^{* *} \\
(0.0042)\end{array}$ & & $\begin{array}{l}0.1320^{* *} \\
(0.0553)\end{array}$ & & $\begin{array}{c}0.9556 \\
(0.7029)\end{array}$ & \\
\hline (2) Overdraft Mention, long duration, with Subsequent Messages & & $\begin{array}{l}0.0154^{* *} \\
(0.0065)\end{array}$ & & $\begin{array}{l}0.1718^{* *} \\
(0.0857)\end{array}$ & & $\begin{array}{c}3.1076^{* * *} \\
(1.1831)\end{array}$ \\
\hline (3) Overdraft Mention, short duration, with Subsequent Messages & & $\begin{array}{l}0.0109^{*} \\
(0.0065)\end{array}$ & & $\begin{array}{l}0.1811^{* *} \\
(0.0853)\end{array}$ & & $\begin{array}{c}0.0711 \\
(1.0163)\end{array}$ \\
\hline (4) Overdraft Mention No Subsequent Messages & & $\begin{array}{c}0.0003 \\
(0.0064)\end{array}$ & & $\begin{array}{c}0.0429 \\
(0.0835)\end{array}$ & & $\begin{array}{l}-0.3108 \\
(1.0420)\end{array}$ \\
\hline (5) Overdraft Mention, with Interest Discount, long duration & $\begin{array}{c}-0.0134^{* * *} \\
(0.0044)\end{array}$ & & $\begin{array}{l}-0.1467^{* * *} \\
(0.0583)\end{array}$ & & $\begin{array}{l}-1.0662 \\
(0.7510)\end{array}$ & \\
\hline (6) Overdraft Mention, with Interest Discount, short duration & $\begin{array}{l}-0.0114^{* *} \\
(0.0044)\end{array}$ & & $\begin{array}{c}-0.1747^{* * * *} \\
(0.0580)\end{array}$ & & $\begin{array}{r}-0.4189 \\
(0.7516)\end{array}$ & \\
\hline (7) Overdraft Mention, with Interest Discount, long duration, with Subsequent Messages & & $\begin{array}{c}-0.0227^{* * *} \\
(0.0069)\end{array}$ & & $\begin{array}{c}-0.2671^{* * *} \\
(0.0910)\end{array}$ & & $\begin{array}{c}-4.2866^{* * * *} \\
(1.2475)\end{array}$ \\
\hline (8) Overdraft Mention, with Interest Discount, short duration, with Subsequent Messages & & $\begin{array}{l}-0.0129^{*} \\
(0.0069)\end{array}$ & & $\begin{array}{c}-0.2533^{* * *} \\
(0.0905)\end{array}$ & & $\begin{array}{c}0.2155 \\
(1.0995)\end{array}$ \\
\hline (9) Overdraft Mention, with Interest Discount, long duration, w/o Subsequent Messages & & $\begin{array}{c}0.0006 \\
(0.0077)\end{array}$ & & $\begin{array}{c}0.1033 \\
(0.1014)\end{array}$ & & $\begin{array}{l}2.3327^{*} \\
(1.3053)\end{array}$ \\
\hline (10) Overdraft Mention, with Interest Discount, short duration, w/o Subsequent Messages & & $\begin{array}{r}-0.0040 \\
(0.0077)\end{array}$ & & $\begin{array}{l}-0.0263 \\
(0.1001)\end{array}$ & & $\begin{array}{r}1.3480 \\
(1.2777)\end{array}$ \\
\hline $\begin{array}{l}\text { (11) No Overdraft Mention = Auto Bill-Pay Discount Only or Debit Card Discount Only } \\
\text { p-value on F-test of equality between rows (2) and (3) }\end{array}$ & Omitted & $\begin{array}{c}\text { Omitted } \\
0.5931\end{array}$ & Omitted & $\begin{array}{l}\text { Omitted } \\
0.9344\end{array}$ & Omitted & $\begin{array}{c}\text { Omitted } \\
0.0371\end{array}$ \\
\hline p-value on F-test of equality between rows (2) and (4) & & 0.0738 & & 0.2454 & & 0.0206 \\
\hline p-value on F-test of equality between rows (3) and (4) & & 0.2094 & & 0.2118 & & 0.7764 \\
\hline p-value on F-test of equality between rows (5) and (6) & 0.6183 & & 0.5858 & & 0.3359 & \\
\hline p-value on F-test of equality between rows (7) and ( 8 ) & & 0.3159 & & 0.9141 & & 0.0068 \\
\hline p-value on F-test of equality between rows (7) and (9) & & 0.0244 & & 0.0065 & & 0.0002 \\
\hline p-value on F-test of equality between rows (7) and (10) & & 0.0711 & & 0.0750 & & 0.0016 \\
\hline p-value on F-test of equality between rows (8) and (9) & & 0.1919 & & 0.0087 & & 0.2145 \\
\hline p-value on F-test of equality between rows (8) and (10) & & 0.3910 & & 0.0926 & & 0.5018 \\
\hline p-value on F-test of equality between rows (9) and (10) & & 0.5010 & & 0.1555 & & 0.4174 \\
\hline Observations & 108000 & 108000 & 108000 & 108000 & 108000 & 108000 \\
\hline
\end{tabular}

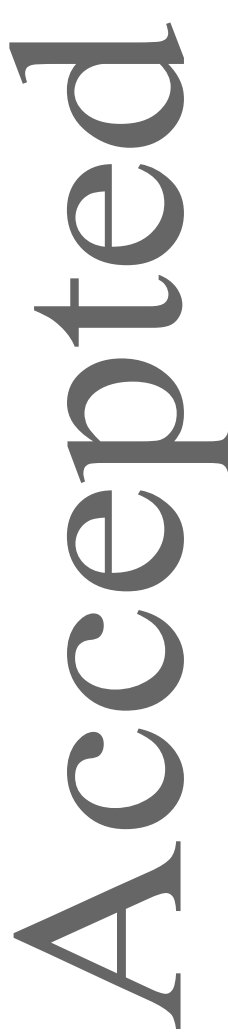

This article is protected by copyright. All rights reserved 